\title{
Talin mechanosensitivity is modulated by a direct interaction with cyclin-dependent kinase-1
}

Received for publication, March 20, 2021, and in revised form, May 20, 2021 Published, Papers in Press, June 9, 2021, https://doi.org/10.1016/j.jbc.2021.100837

\author{
Rosemarie E. Gough ${ }^{1, \neq} \oplus$, Matthew C. Jones ${ }^{2, \neq}$, Thomas Zacharchenko ${ }^{2}$, Shimin Le ${ }^{3}$, Miao $\mathrm{Yu}^{3}$, \\ Guillaume Jacquemet ${ }^{4,5}$, Ste P. Muench ${ }^{6}$, Jie $\operatorname{Yan}^{3,7}$, Jonathan D. Humphries ${ }^{2}$, Claus Jørgensen ${ }^{8}$, \\ Martin J. Humphries ${ }^{2, *} \mathbb{D}$, and Benjamin T. Goult ${ }^{1, *}$ (1)
}

From the ${ }^{1}$ School of Biosciences, University of Kent, Canterbury, Kent, UK; ${ }^{2}$ Faculty of Biology, Medicine \& Health, Wellcome Centre for Cell-Matrix Research, Manchester Academic Health Science Centre, University of Manchester, Manchester, UK; ${ }^{3}$ Mechanobiology Institute, National University of Singapore, Singapore; ${ }^{4}$ Faculty of Science and Engineering, Cell Biology Department, Åbo Akademi University, Turku, Finland; ${ }^{5}$ Turku Bioscience Centre, University of Turku and Åbo Akademi University, Turku, Finland; ${ }^{6}$ School of Biomedical Sciences, Astbury Centre for Structural Biology, University of Leeds, Leeds, UK; ${ }^{7}$ Department of Physics, National University of Singapore, Singapore; ${ }^{8}$ Cancer Research UK Manchester Institute, The University of Manchester, Manchester, UK

Edited by Karen Fleming

Talin (TLN1) is a mechanosensitive component of adhesion complexes that directly couples integrins to the actin cytoskeleton. In response to force, talin undergoes switch-like behavior of its multiple rod domains that modulate interactions with its binding partners. Cyclin-dependent kinase-1 (CDK1) is a key regulator of the cell cycle, exerting its effects through synchronized phosphorylation of a large number of protein targets. CDK1 activity maintains adhesion during interphase, and its inhibition is a prerequisite for the tightly choreographed changes in cell shape and adhesion that are required for successful mitosis. Using a combination of biochemical, structural, and cell biological approaches, we demonstrate a direct interaction between talin and CDK1 that occurs at sites of integrin-mediated adhesion. Mutagenesis demonstrated that CDK1 contains a functional talin-binding LD motif, and the binding site within talin was pinpointed to helical bundle R8. Talin also contains a consensus CDK1 phosphorylation motif centered on S1589, a site shown to be phosphorylated by CDK1 in vitro. A phosphomimetic mutant of this site within talin lowered the binding affinity of the cytoskeletal adaptor KANK and weakened the response of this region to force as measured by single molecule stretching, potentially altering downstream mechanotransduction pathways. The direct binding of the master cell cycle regulator CDK1 to the primary integrin effector talin represents a coupling of cell proliferation and cell adhesion machineries and thereby indicates a mechanism by which the microenvironment can control cell division in multicellular organisms.

Cell adhesion to the extracellular matrix (ECM) is required for anchorage-dependent cell survival and growth in multicellular organisms. During the G1 commitment phase of the

\footnotetext{
₹ These authors contributed equally to this work.

* For correspondence: Benjamin T. Goult, b.t.goult@kent.ac.uk; Martin J. Humphries, martin.humphries@manchester.ac.uk.
}

cell cycle, adhesion signaling is required to initiate DNA synthesis $(1,2)$ and suppress apoptosis $(3,4)$. However, how changes in adhesion signaling are able to influence cell cycle progression in adherent cells is only partly elucidated. During mitosis, major changes in integrin adhesion complexes (IACs), cytoskeletal architecture, and cell shape are obligatory for chromosome segregation and cytokinesis (5-8). These remodeling events can be so extensive that cells become round and virtually lose their adhesion. Despite the risks to tissue integrity, the optimally symmetrical geometry of a sphere appears to enable the high degree of precision required for chromosome capture and division plane orientation (9-11). Suppression of these changes during mitosis perturbs the ability of cells to divide accurately (12-14). All of these changes are highly conserved, implying the existence of a primordial regulatory mechanism linking the cell cycle and adhesion machineries.

One link between the cell cycle and adhesion is mediated through the master regulator of the cell cycle, cyclindependent kinase-1 (CDK1). CDK1 is a serine/threonine kinase that partners with cyclins that control both kinase activity and substrate specificity (15). CDK1 inhibition leads to disassembly of IACs, suggesting that CDK1 activity has an interphase role in promoting integrin-mediated adhesion and actomyosin organization $(12,16)$. IAC area increases during $S$ phase in a CDK1-dependent manner, then inhibition of CDK1 through Wee1-mediated phosphorylation in G2 causes IAC loss in preparation for entry into mitosis (12). Together, these findings identify a key role for CDK1 in the regulation of adhesion during cell cycle progression.

Talins are large $(270 \mathrm{kDa})$ multidomain proteins composed of an N-terminal head coupled to a large rod comprising 13 helical bundles (R1-R13) (17). The two talin isoforms (talin-1/ TLN1 and talin-2/TLN2) are considered to be the principal proteins that couple integrins to F-actin. The $\mathrm{N}$-terminal FERM domain binds to integrin cytoplasmic domains (18-21), and two sites in the C-terminal flexible rod domain bind 


\section{A direct interaction between talin and CDK1}

F-actin $(22,23)$. Talin binding to integrins is maintained by actomyosin-generated force and results in conformational activation of integrins (20). The linkage therefore provides a regulatable means of controlling cell adhesion to the ECM from within the cell. This trimolecular core also initiates the recruitment of a large number of additional proteins, termed the adhesome, which varies in composition between IAC type (24-26), reflecting distinct effector, signaling, and mechanosensing functions. The role of talin as a key mechanotransducer relies on its ability to undergo force-dependent structural rearrangements. As force from actin is exerted on talin anchored to integrins, the talin rod gradually unfolds at discrete sites, resulting in both the displacement and recruitment of signaling proteins. This enables talin to serve as a mechanosensitive signaling hub, integrating a wide range of signals to produce diverse cellular responses (27).

Here, we identify a direct interaction between CDK1 and talin through an unbiased analysis of talin-binding proteins. CDK1 contains a talin-binding LD motif that interacts directly with the R8 domain of talin. This interaction is required for regulating CDK1 function at IACs and leads to an alteration in the mechanosensitivity of talin. Direct mechanical coupling of the master cell cycle regulator and the principal integrin effector provides an elegant mechanism coupling the cell division and adhesion machineries to facilitate proliferation in a multicellular environment.

\section{Results}

\section{Talin associates with CDK1 at adhesion sites}

To identify novel talin-binding proteins, full-length talin-1 fused to GFP was expressed in U2OS cells and interacting proteins identified by GFP-Trap pull-down and mass spectrometry. Multiple proteins were identified, including previously characterized ligands such as vinculin, integrins, and two of the four KANK (KN Motif and Ankyrin Repeat Domains) proteins, KANK2 and KANK3 (Fig. $1 A$ and Table S1). In addition, peptides covering a large proportion of CDK1 (SAINT Score 0.96) were detected with high confidence in all three talin pull-downs, but never in the GFP controls, suggesting that CDK1 also associates with talin. The mass spectrometry data were confirmed by western blotting of the GFPtalin pull-down with anti-CDK1 antibody (Fig. 1B). To support these findings, CDK1 was tagged with BirA*, expressed in U2OS cells, and BioID proximity biotinylation employed to label proteins close to CDK1 in situ. Using this approach, 118 labeled proteins were identified, including the known CDK1 interactors, cyclin B1 and cyclin B2 (Table S2). 47\% of the identified proteins were found within the meta adhesome, suggestive of a role for CDK1 in regulating adhesion/cytoskeletal dynamics (28). Furthermore, in addition to talin, the core adhesome components, vinculin, paxillin, filamin $\mathrm{A}$, and CRK, were in close proximity to CDK1 (Fig. 1C). Finally, TIRF microscopy was employed to determine the localization of CDK1 at the cell-ECM interface. mScarlet-CDK1 was distributed in elongated, fleck-like structures that partially overlapped with GFP-talin-containing IACs (Fig. 1D). Taken together, these findings indicate a close association between talin and CDK1 at sites of integrin-mediated adhesion to the ECM.

\section{CDK1 contains an LD motif that binds directly to talin $R 8$}

We next aimed to identify the binding interface between talin and CDK1. Talin contains multiple binding sites for proteins that contain leucine/aspartic acid LD motifs, with a consensus sequence I/LDxØØxØØ (where $\varnothing$ denotes a hydrophobic residue) $(29,30)$. These amphipathic helical peptide motifs engage talin via a helix-addition mechanism $(31,32)$, packing on the side of the helical bundles in the talin rod. This mode of binding allows mechanosensitive regulation as it only occurs when the talin rod domain mediating the interaction is folded: unfolding due to mechanical force disrupts the LD motif binding site and the connection is severed (27).

Analysis of the CDK1 protein sequence identified a highly conserved, consensus LD motif sequence between residues 206 and 223 (Fig. 2, $A$ and $B$ ), which we postulated might bind directly to talin. Fluorescence polarization was employed to test direct binding, as described previously $(33,34)$. In this assay, a synthetic peptide spanning the CDK1 LD motif, CDK1(206-223), is fluorescently tagged and titrated against an increasing concentration of unlabeled talin fragment; any binding between the two polypeptides results in an increase in the fluorescence polarization signal. To identify the putative CDK1-binding site(s) on talin, six talin fragments were generated that span the whole molecule; F0-F3, R1-R3, R4R8, R9-R10, R11-R12 and R13-DD (Fig. 2C). Two of these fragments incorporate the actin-binding sites in the talin rod, ABS2 (R4-R8 $(23,35)$ ) and ABS3 (R13-DD $(36,37))$. No significant interaction was observed between CDK1(206-223) and the talin Head, R9-R10, R11-R12, or R13-DD fragments; however, R4-R8 demonstrated increasing fluorescence polarization with increasing talin concentration, indicative of a direct interaction (Fig. 2D). We note that a small change in polarization was also detected with the R1-R3 fragment; however, this interaction was too weak to be quantified and is possibly the result of a nonspecific LD interaction with the LD motif binding sites in R2 and R3 that bind the LD motifs in RIAM (17). To further define the CDK1-binding site within talin R4-R8, we tested binding to additional rod domain constructs. Talin R4-R6 demonstrated negligible binding to CDK1(206-223), whereas R7R8 bound to CDK1(206-223) with a Kd of $15 \mu \mathrm{M}$ (Fig. 2E). The R7R8 region of both talin isoforms, talin-1 and talin-2, bound CDK1(206-223) with similar affinity (Fig. 2E). As found for other LD motif peptides (34), mutation of the LD motif within CDK1 to two alanine residues (to generate a $2 \mathrm{~A}$ mutant; Fig. $3, A$ and $B$ ) markedly reduced the interaction with talin (Fig. 3C).

\section{The CDK1 LD motif binding pocket on talin $R 8$ differs from that of DLC1 and RIAM}

We initially used NMR to characterize the interaction between CDK1 and talin. HSQC spectra of ${ }^{15} \mathrm{~N}$-labeled talin-1 
A

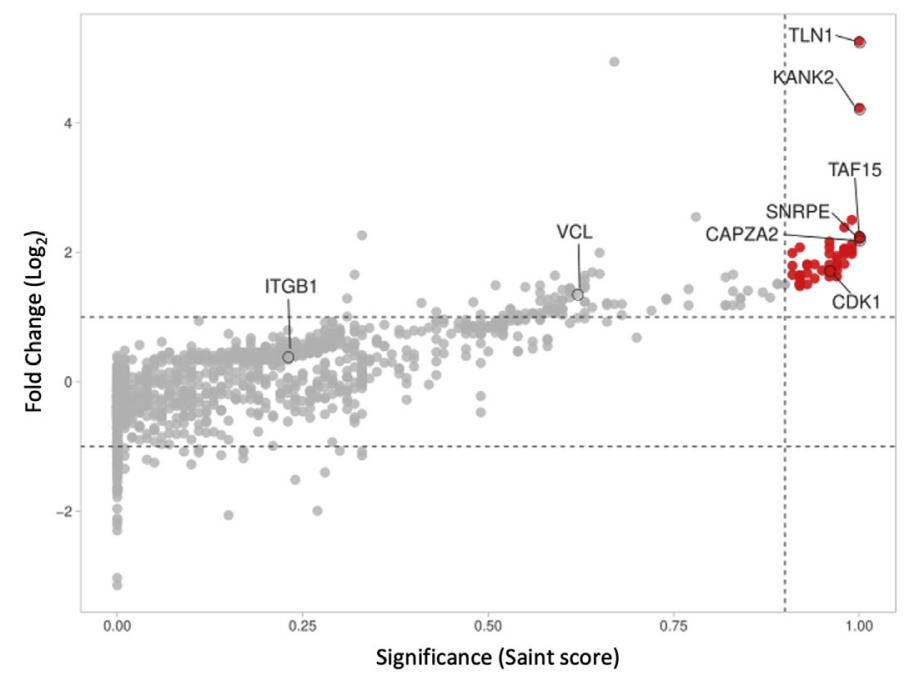

B

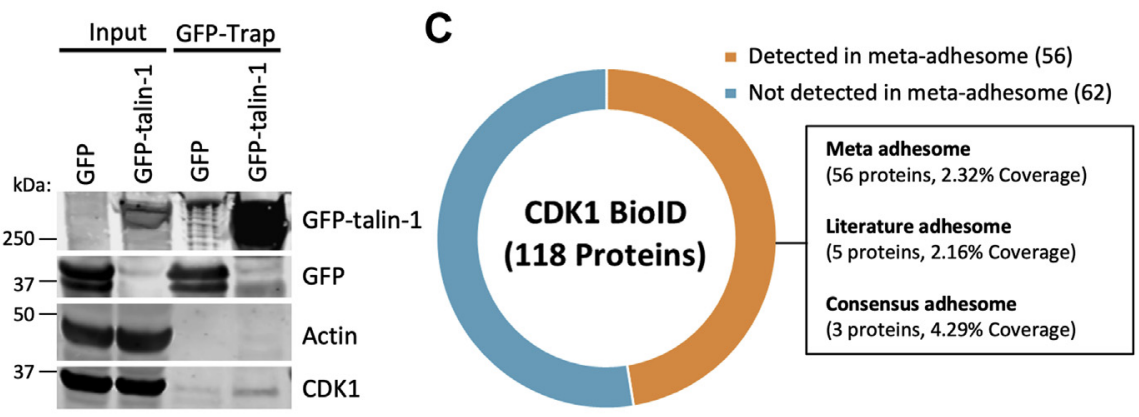

\begin{tabular}{|l|c|c|c|}
\hline Adhesome protein & Mean BirA Intensity & Mean CDK1 Intensity & Mean Enrichment Score \\
\hline \hline Paxillin & 23207.4 & 50064.0 & 2.2 \\
\hline CRK & 25855.8 & 166943.1 & 12.0 \\
Vinculin & 300341.6 & 5190646.5 & 18.1 \\
Talin-1 & 7081362.4 & 13776303.8 & 2.0 \\
Filamin-A & 66756238.9 & 140623289.4 & 2.2 \\
\hline
\end{tabular}

D

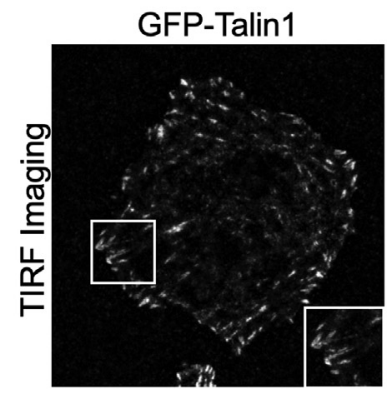

mScarlet-CDK1 Talin1 CDK1
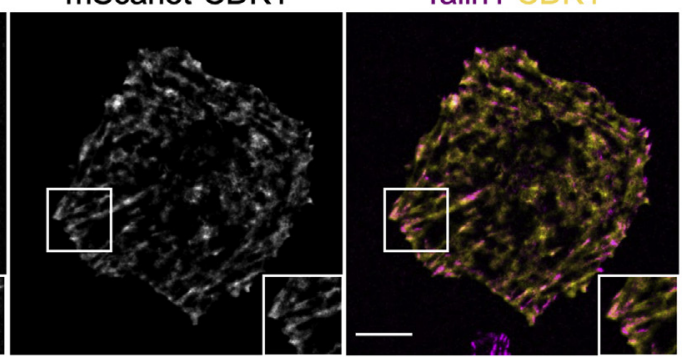

Figure 1. Talin interacts with CDK1. A, Mass Spectrometry (MS) analysis of GFP-tagged talin-1 binding proteins, displayed as a volcano plot. The foldchange enrichment over GFP alone is plotted against the significance of the association. The SAINT score and the FC_B scores were calculated using the REPRINT (Resource for Evaluation of Protein Interaction Network) online tool (https://reprint-apms.org/). The volcano plot was generated using VolcaNoseR (70). Key putative talin-1 binders, including CDK1, are highlighted. B, GFP-Trap pull-down of GFP alone or GFP-talin-1 expressed in U2OS cells followed by western blotting for GFP, actin, and CDK1. C, MS analysis of proteins biotinylated by BirA*-CDK1, indicating proteins in close proximity to CDK1 in cells. Proteins shown in the table are core components of IACs. D, TIRF image of a U2OS cell coexpressing GFP-talin-1 and mScarlet-CDK1. Scale bar $10 \mu \mathrm{m}$.

R7R8 were collected in the absence and presence of increasing amounts of CDK1(206-223) peptide (Fig. 3D). Addition of CDK1(206-223) peptide, but not CDK1-2A, resulted in progressive chemical shift changes to a subset of the $\mathrm{R} 8$ residues, indicative of a direct, specific interaction. Using the chemical shift assignments of the R8 domain of talin-1 (BMRB ID:19339 (32)), the changes were mapped onto the structure of R8 (PDB ID: 2X0C (38)). The changes mapped onto one face of the R8 domain, the same region that binds the LD motifs of DLC1 (32) and RIAM $(17,39)$ (Fig. 3E). To support the requirement for the talin R8 domain in interacting with CDK1, GFP-Trap pull-downs were performed using wild-type (WT) full-length talin or talin lacking the R8 domain $(\triangle \mathrm{R} 8)$. WT-talin-1-GFP pulled down HA-tagged CDK1-WT, but not HA-CDK1-2A, whereas $\triangle \mathrm{R} 8$-talin-1-GFP failed to associate with HA-CDK1WT (Fig. 3F). 
A

$\begin{array}{lccccccccccccc}\text { Consensus } & X & X & E & \text { L } & \text { D } & \text { X } & \text { L } & \text { L } & \text { X } & \text { X } & \text { L } & X & X \\ \text { PXN LD1 } & \text { M } & \text { D } & \text { D } & \text { L } & \text { D } & \text { A } & \text { L } & \text { L } & \text { A } & \text { D } & \text { L } & \text { E } & \text { S } \\ \text { RIAM } & \text { S } & \text { E } & \text { D } & \text { I } & \text { D } & \text { Q } & \text { M } & \text { F } & \text { S } & \text { T } & \text { L } & \text { L } & \text { G } \\ \text { DLC1 } & \text { F } & \text { P } & \text { E } & \text { L } & \text { D } & \text { D } & \text { I } & \text { L } & \text { Y } & \text { H } & \text { V } & \text { K } & \text { G } \\ \text { KANK1 } & \text { Q } & \text { L } & \text { D } & \text { L } & \text { D } & \text { F } & \text { V } & \text { K } & \text { Y } & \text { V } & \text { D } & \text { D } & \text { I } \\ \text { KANK2 } & \text { R } & \text { L } & \text { D } & \text { L } & \text { D } & \text { F } & \text { L } & \text { K } & \text { Y } & \text { V } & \text { D } & \text { D } & \text { I } \\ \text { CDK1 } & \text { D } & \text { S } & \text { E } & \text { I } & \text { D } & \text { Q } & \text { L } & \text { F } & \text { R } & \text { I } & \text { F } & \text { R } & \text { A }\end{array}$

B

HUMAN AELATKKPLFHGDSEIDQLFRIFRALGTPNNEVWPEVESL MOUSE AELATKKPLFHGDSEIDQLFRIFRALGTPNNEVWPEVESL DROME AEMATRKPLFQGDSEIDQLFRMFRILKTPTEDIWPGVTSL DICDI GEMLNKKPLFSGDCEIDQIFRIFRVLGTPDDSIWPGVTKL CAEEL AEMATKKPLFQGDSEIDELFRIFRVLGTPTELEWNGVESL YEAST AEMCNRKPIFSGDSEIDQIFKIFRVLGTPNEAIWPDIVYL

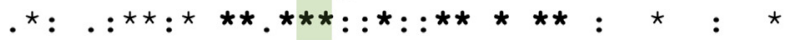

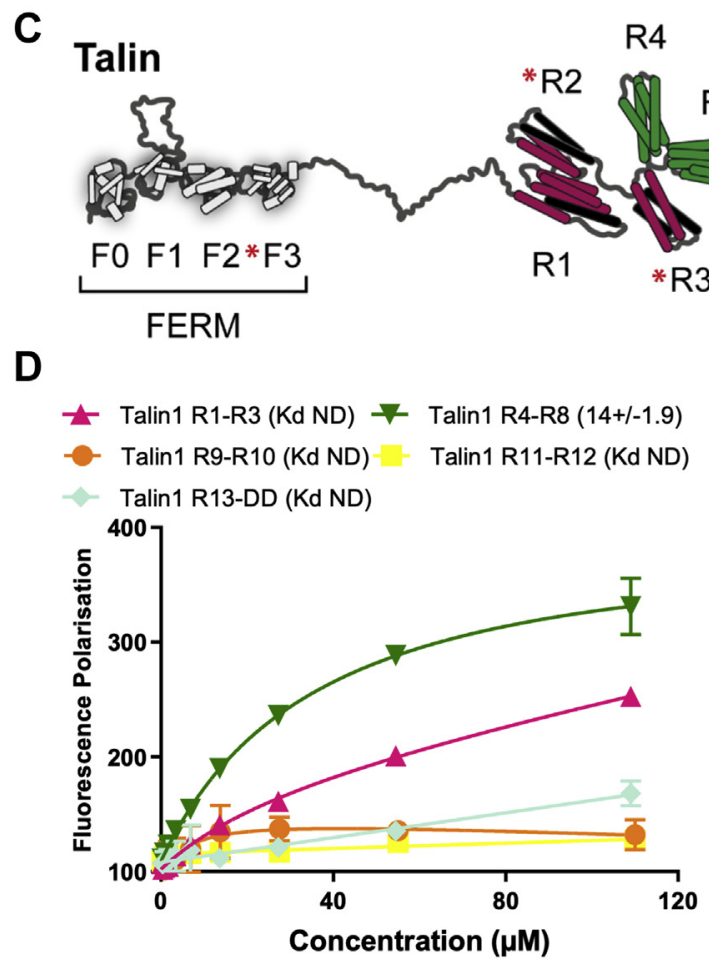

$E$
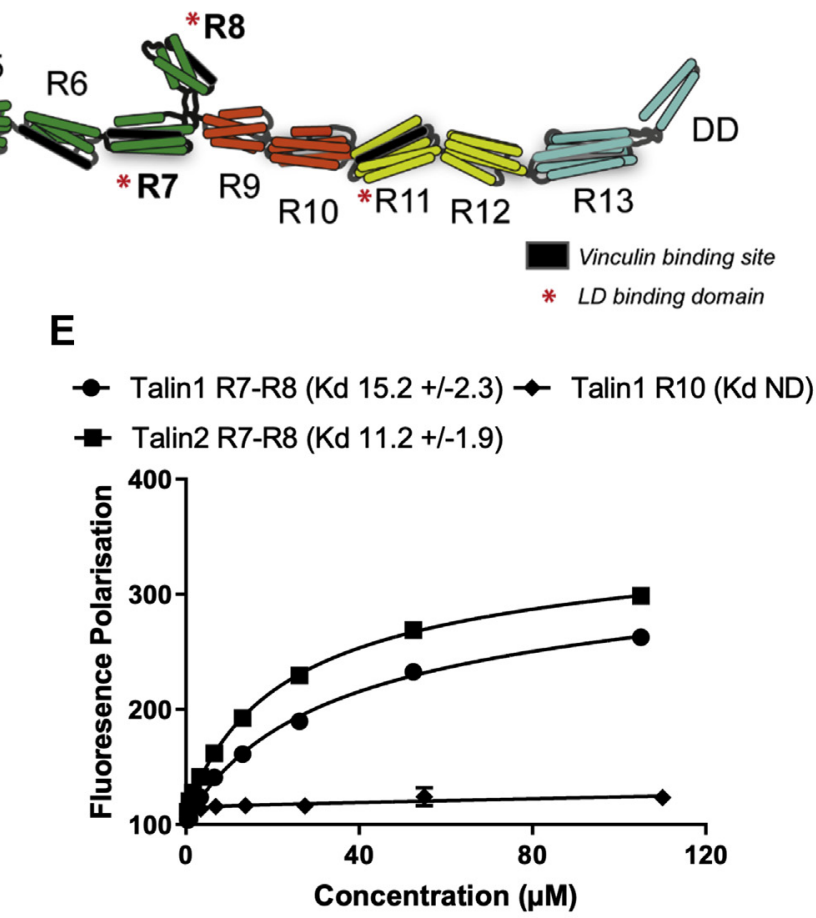

Figure 2. CDK1 interacts with the talin R8 domain. $A$, sequence alignment of the previously reported talin-binding LD motifs, paxillin LD1, RIAM, DLC1, KANK1, and KANK2, with CDK1. Acidic (red), basic (blue), and hydrophobic (green) residues are highlighted. $B$, sequence alignment of the CDK1 region containing the talin binding site. The talin-binding LD motif is highlighted in bold. Aligned sequences were human (UniProt P06493), mouse (UniProt P11440), Drosophila melanogaster (UniProt P23572), Dictyostelium discoideum (UniProt P34112), Caenorhabditis elegans (UniProt P34556), and Saccharomyces cerevisiae (UniProt P00546). C, schematic of the domain structure of talin. The five talin rod fragments screened for binding to CDK1 are highlighted: R1-R3 (residues 482-911, pink), R4-R8 (residues 913-1653, green), R9-R10 (residues 1655-2015, orange), R11-R12 (1974-2293, yellow), and R13-DD (2300-2542, cyan). The 11 vinculin-binding sites are shown in black. The LD-binding domains identified to date are shown by a red asterisk. $D$ and $E$, binding of BODIPYlabeled CDK1(206-223) peptide to talin fragments measured using fluorescence polarization. Binding of BODIPY-labeled CDK1(206-223) peptide with (D) the five talin-1 fragments and $(E)$ with talin-1 and talin-2 R7R8 domains. Dissociation constants $\pm S E(\mu M)$ for the interactions are indicated in the legend. All measurements were performed in triplicate. ND, not determined.

To resolve the structural basis of the talin-CDK1 interaction, the R7R8-CDK1 peptide complex was crystallized and the structure determined to $2.28 \AA$ resolution (Fig. $4, A$ and $B$ ). The structure contained two R7R8 molecules within the asymmetric unit, each with CDK1 peptides localized to the respective $\mathrm{R} 8$ domains (Fig. $\mathrm{S} 1 A$; Table $\mathrm{S} 3$ ). Each peptide was exceptionally resolved in both the $\mathrm{F}_{0}-\mathrm{F}_{\mathrm{C}}$ weighted difference map and simulated annealing OMIT maps (Fig. S1, $B$ and $C$ ). Unexpectedly, the CDK1 peptide was oriented perpendicular to the helices of the R8 fold, forming a pseudo-5-helix bundle (Fig. 4, $A$ and $B$ ) that contrasts with the helix-addition mechanism of DLC1 and RIAM $(32,39)$ (Fig. 4, $C$ and $D$ ). This arrangement was supported by NMR chemical shift mapping (Fig. 3E), where the shift changes upon addition of CDK1 peptide were located predominantly at one end of the LD motif binding surface of the bundle.
The CDK1 peptide was identified on the basis of sequence homology with the LD motif. In previous studies of LD motif recognition, the aspartate residue of the LD motif was shown to form a salt bridge with a positively charged residue on the cognate-binding site (40), and in the case of DLC1, mutation of talin K1544 abolished interactions with R8 (32). The CDK1talin structure deviated from this shared interaction mechanism as K1544 was not involved in the interaction, but instead oriented away from the CDK1-binding site. The isoleucine side chain of the LD motif was responsible for displacing the K1544 side chain and an ID/AA double mutation attenuated the CDK1-talin interaction (Fig. 4B). The remainder of the CDK1 peptide formed a hydrophobic interface with the R8 domain with the CDK1 ${ }^{214}$ FRIFRA $^{219}$ sequence buried into a hydrophobic groove between the helices formed of talin residues L1492, A1495, V1498, L1539, V1540, and I1543 (Fig. 4B). 
A

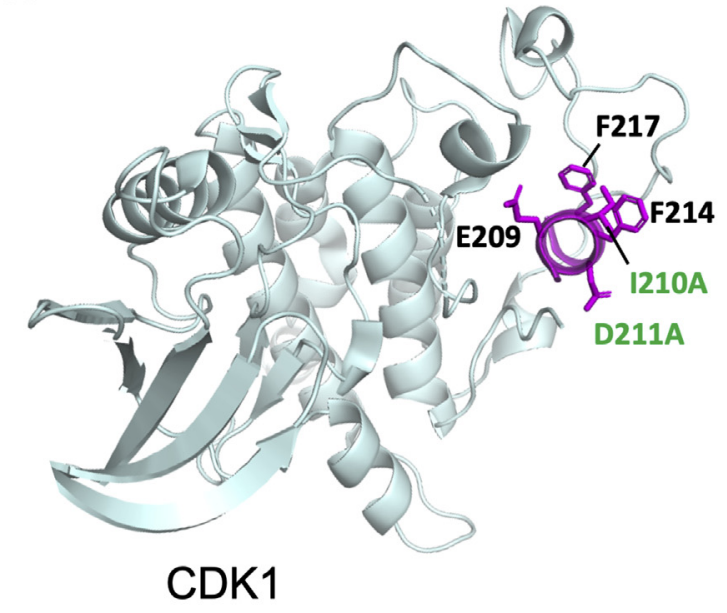

B

$\begin{array}{lll}\text { CDK1 WT } & 206 \_223 C & \text { GDSEIDQLFRIFRALGTPC } \\ \text { CDK1-2A } & 206-223 C \text { GDSEAAQLFRIFRALGTPC }\end{array}$

C

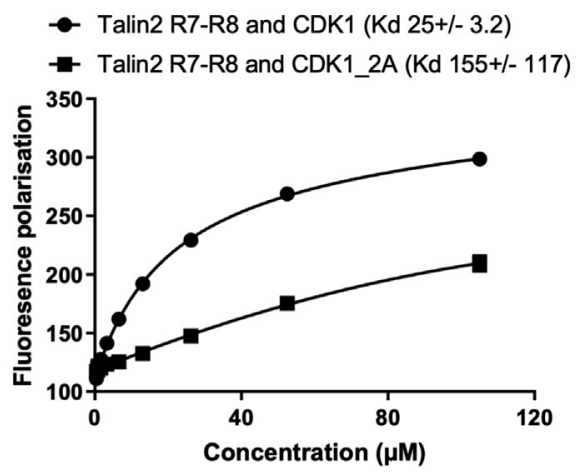

D

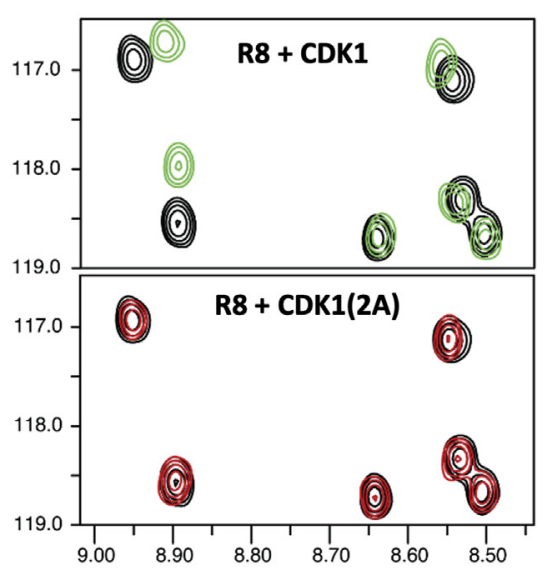

E

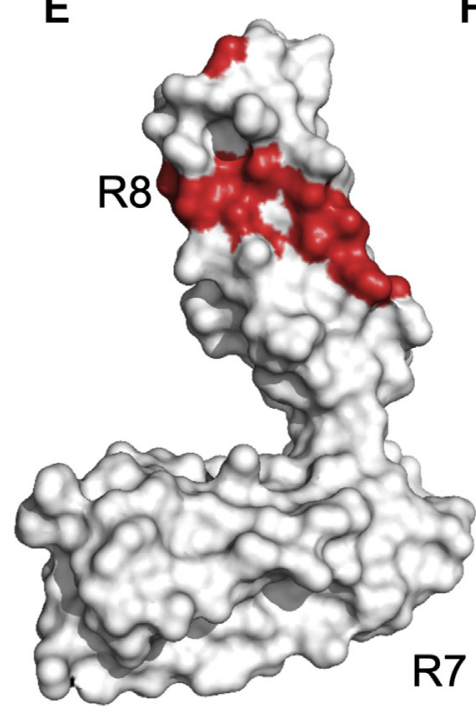

$\mathbf{F}$

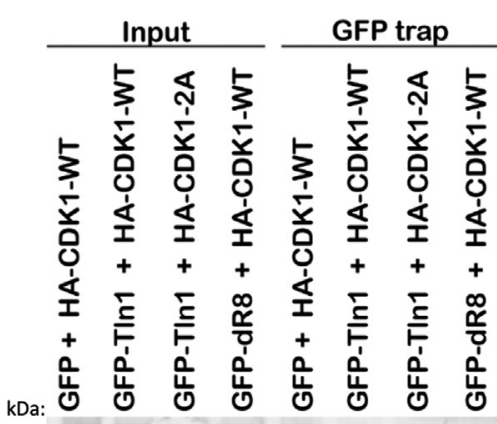
250$37-$

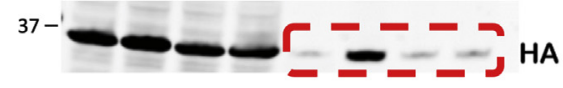

Figure 3. The CDK1 LD motif is required for CDK1 binding to talin-1. $A$, CDK1 structure (PDB ID: 4YC3 (41)) with the talin-binding LD motif highlighted in magenta. The LD motif consensus residues (E209, I210, D211, F214, and F217) and the I210A and D211A, 2A mutation are highlighted. B, aligned sequences of CDK1 WT and CDK1-2A mutant peptides. C, binding of BODIPY-labeled CDK1 WT and 2A 206 to 223 peptide with talin-1 R7R8 domains using fluorescence polarization. Dissociation constants \pm SE $(\mu \mathrm{M})$ for the interactions are indicated. All measurements were performed in triplicate. $D,{ }^{1} H^{15}{ }^{15} \mathrm{~N} H S Q C$ spectra of $70 \mu \mathrm{M}{ }^{15} \mathrm{~N}$-labeled talin-1 R8 (residues 1461-1580) (black) with $420 \mu \mathrm{M}$ CDK1 peptide (green), $420 \mu \mathrm{M}$ CDK1-2A peptide (red) added. E, mapping of the CDK1-binding site on R8 as detected by NMR using weighted chemical shift differences (red) - mapped onto the R7R8 structure. F, GFP-Trap pull-downs from cells expressing GFP alone, GFP-WT-talin-1, or GFP- $\triangle$ R8-talin-1 along with HA-tagged WT or 2A-CDK1, followed by western blotting for GFP and HA.

The CDK1 sequence formed an amphipathic helix that closely resembled its conformation in full-length CDK1 (PDB ID: 4YC6 (41)), where the key residues involved in talin binding are surface exposed (Fig. S2). The structure of this lobe of the kinase has been solved in complex with other proteins such as CKS1 (cyclin-dependent regulatory subunit 1) (41), suggesting it may play a role as a targeting domain. As the CDK1 LD motif peptide superimposed on the CDK1 structure, it was possible to model the interaction between talin and the CDK1-cyclin B1 complex (Fig. 4, $E$ and $F$ ). This demonstrated that the talin-CDK1 interaction is unlikely to perturb CDK1 binding to regulatory cyclin proteins and suggests the possibility that talin is able to interact with active CDK1-cyclin complexes.

\section{Talin binding is required for CDK1-dependent regulation of adhesion}

We previously demonstrated that CDK1 kinase activity is required to maintain IACs and to facilitate changes in IAC area during cell cycle progression (12). To test whether these functions were dependent on the interaction between CDK1 and talin, the effects of mutant versions of both proteins were determined. Consistent with previous data, knockdown of CDK1 in asynchronous cells resulted in a reduction in paxillin-positive IAC area that was rescued by re-expression of siRNA-resistant WT CDK1, but not CDK12A (which is unable to bind talin; Fig. S3, $A$ and $B$ ). In addition, in synchronized cells expressing CDK1-WT, the robust IAC growth previously observed during $\mathrm{S}$ phase did 
A

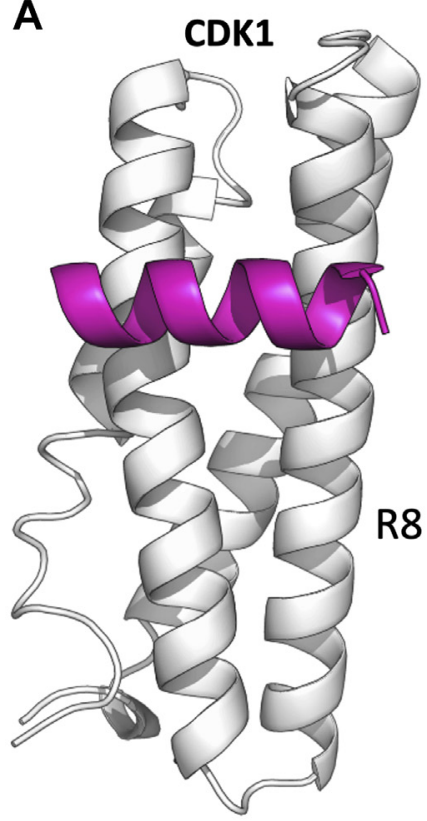

Talin
B

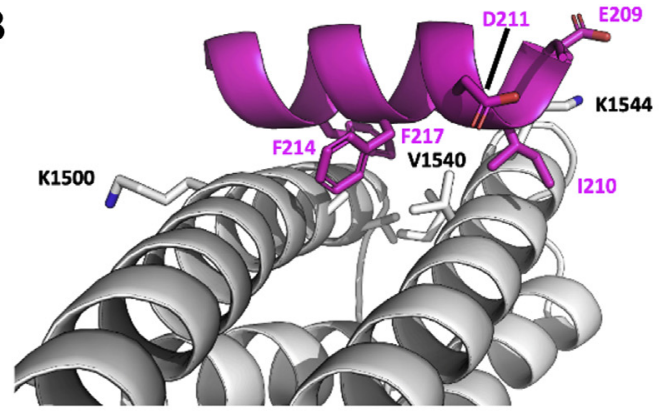

C

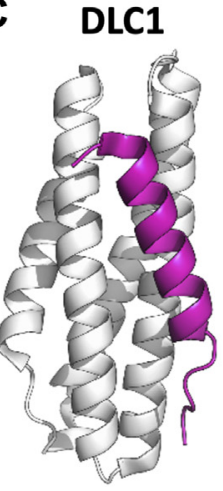

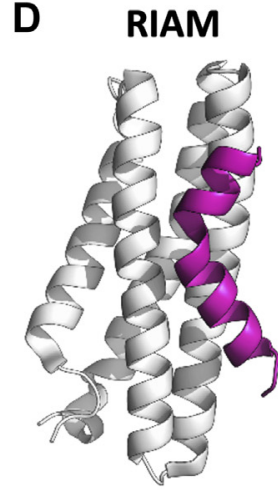

E

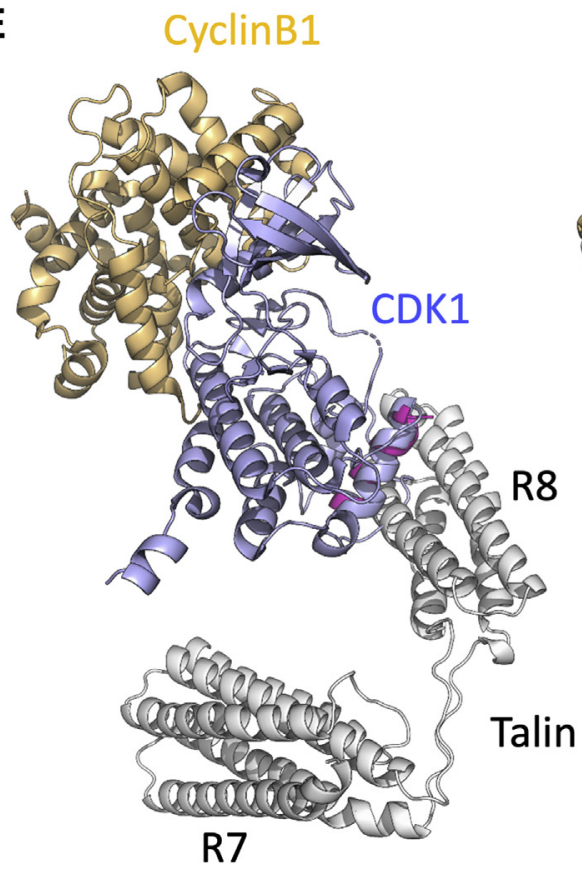

F CyclinB1

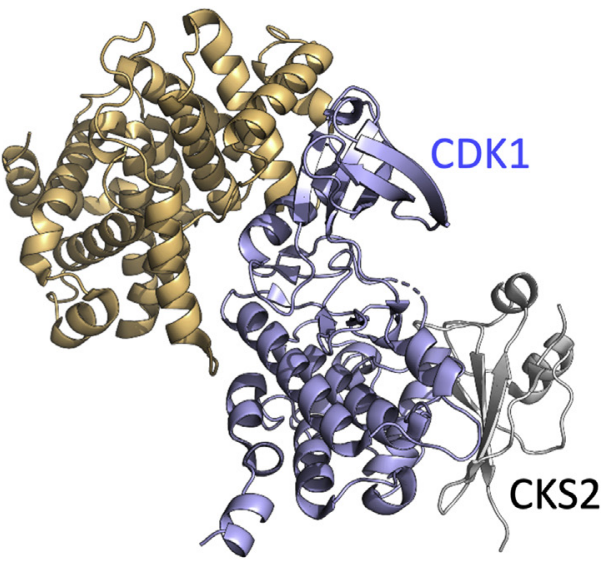

Figure 4. Crystal structure of the talin-CDK1 complex. $A$ and $B$, cartoon representation of the X-ray structure of the talin R7R8 fragment complex with CDK1 (206-223). Talin R8 (white) and CDK1 (magenta) are indicated. $A$, face on and $B$, side on views. Key residues are highlighted. $C$ and $D$, structure of talin R8-LD motif complexes. C, talin-DLC1 (PDB ID: 5FZT (32)) and D, talin-RIAM (PDB ID: 4W8P (39)), orientated as in ( $A$ ). $E$ and $F$, structural model of a talin-CDK1cyclin complex. E, modeled structure of talin (gray) bound to the complex of CDK1 (blue) and cyclin B1 (orange) using (PDB ID: 4YC3 (41)). F, structure of the tripartite complex of CDK1 (blue), cyclin B1 (orange), and CKS2 (gray) (PDB ID: 4YC3). Talin R8 and CKS2 both bind CDK1 via the same region on the opposite face to the cyclin-binding surface.

not occur in cells expressing CDK1-2A (Fig. S3C). These findings indicate that the CDK1 LD motif is required for CDK1 to maintain IACs in asynchronous cells and to facilitate IAC growth during $S$ phase. Subsequent analysis of the CDK1-2A mutant protein demonstrated complexing with cyclin B1, but not cyclin A2, and a lack of phosphorylation at the activating site T161 (Fig. S3, D and $E$ ). While talin binding may therefore contribute to CDK1 activation, since CDK1-cyclin A2 maintains IACs (9), it therefore cannot be concluded that the effects of CDK1-2A on adhesion are solely attributable to the loss of CDK1 binding to talin. 


\section{A direct interaction between talin and CDK1}

In complementary studies, the effects of $\Delta \mathrm{R} 8$-talin-1 expression on IACs were examined. In cells expressing WT talin-1, a dose-dependent reduction in IAC area was observed following treatment of cells with the CDK1 inhibitor RO3306. In contrast, no loss of IAC area was observed in cells expressing $\Delta$ R8-talin-1 (Fig. 5, $A$ and $B$ ). Furthermore, in synchronized cells expressing $\triangle \mathrm{R} 8$-talin-1, IAC area remained constant through G1, S, and G2, while cells expressing WT talin-1 displayed IAC growth during $\mathrm{S}$ (Fig. 5C). These data demonstrate that the talin $\mathrm{R} 8$ domain is required for facilitating CDK1-dependent regulation of IACs.

\section{CDK1 phosphorylates talin R7R8 and modulates its mechanosensitivity}

Talin R8 binds to CDK1 in a similar region to the regulatory CKS proteins that target CDK1 to specific substrates and facilitate CDK1-dependent phosphorylation (41, 42). We therefore hypothesized that binding of CDK1 to talin might

A
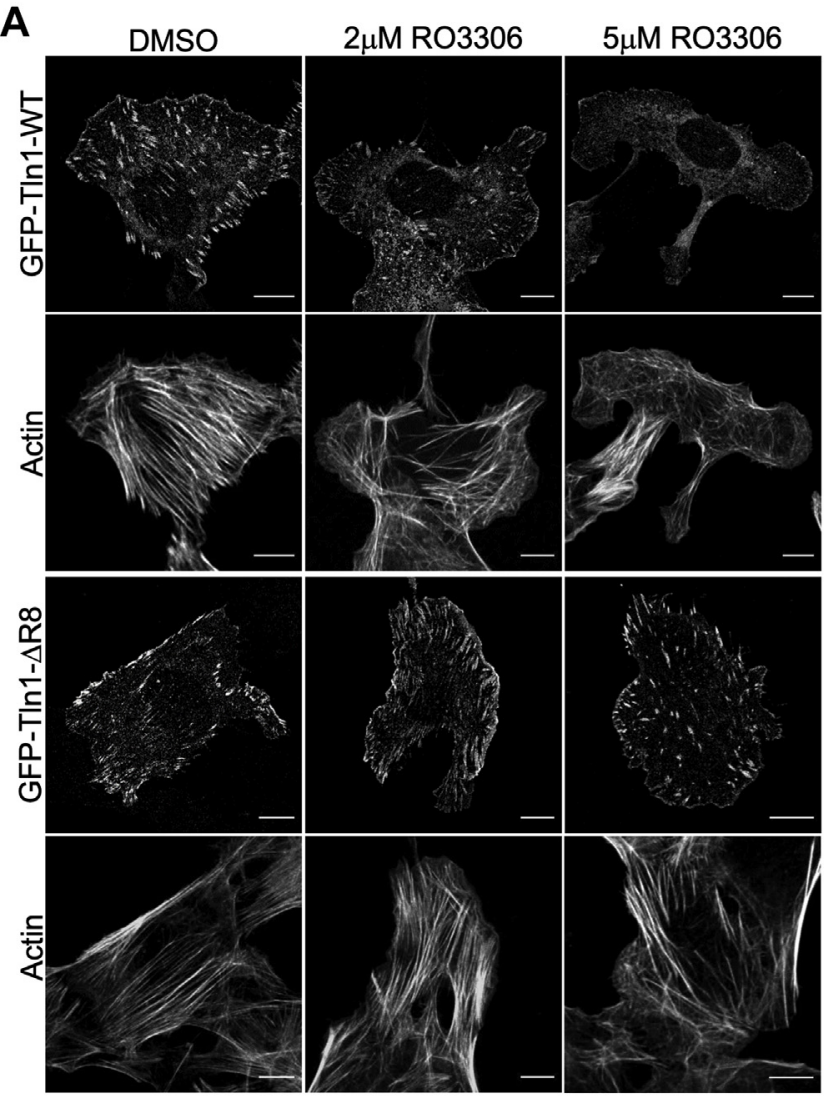

B

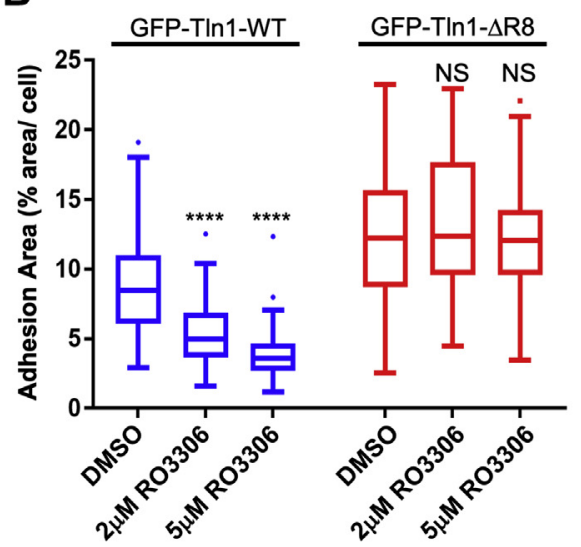

C

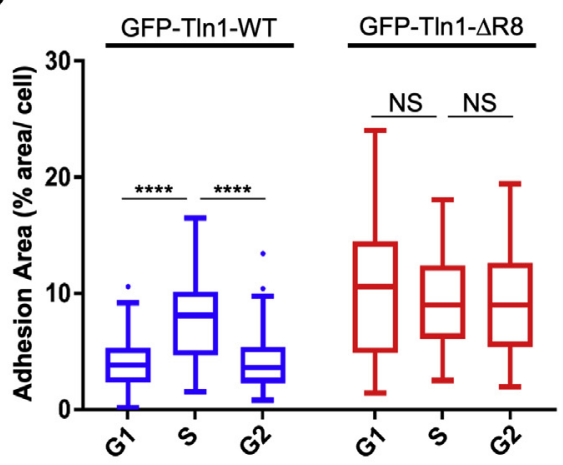

Figure 5. Talin-CDK1 interaction is required to facilitate CDK1-dependent regulation of adhesion complexes. $A$, confocal imaging of U2OS cells expressing GFP-WT-talin-1 or GFP- $\triangle$ R8-talin-1 treated with DMSO or two different doses of the CDK1 inhibitor RO3306. Bars $10 \mu \mathrm{m}$. $B$, IAC area changes in cells treated with DMSO or RO3306. C, IAC area changes in G1, S, and G2 phase for cells expressing GFP-WT-talin-1 or GFP- $\triangle$ R8-talin-1. For $B$ and $C$, a minimum of 50 cells per condition was used for analysis and results are displayed as Tukey box and whisker plots (whiskers represent 1.5x interquartile range). ${ }^{* * * *} p<0.0001$. 
lead to phosphorylation of residues within the R7R8 region. Incubation of talin-1 R7R8 and CDK1-cyclin A with ATP in vitro resulted in a high level of phosphorylation of R7R8 (Fig. 6, $A$ and $B$ ), and subsequent analysis by mass spectrometry identified a single phosphorylation at S1589. Furthermore, sequence analysis identified the presence of a consensus CDK1 phosphorylation motif (SP) at S1589 (Fig. 6, B-D).

The positioning of the talin-1 phosphorylation site is at the end of the R7 rod domain close to where R8 is inserted (Fig. 6, C and $D)$, and is adjacent to two charged residues D1451 and E1591. We predicted that phosphorylation of S1589 might lead to repulsion from these acidic residues, resulting in decreased stability of both R7 and R8 and a potential weakening of the binding of ligands to R7R8. To determine if S1589 phosphorylation affected the binding of KANK to R7 and DLC1 and CDK1 binding to R8 $(32,34)$, a talin phosphomimetic mutant (S1589D) was designed and the binding affinity of the CDK1, KANK, and DLC1 peptide ligands to R7R8 measured by fluorescence polarization. Binding of both R8 ligands was largely unaffected by the talin-1 S1589D mutation, but the affinity of KANK binding was approximately fourfold lower $(\mathrm{Kd} 4 \mu \mathrm{M}$ and $1 \mu \mathrm{M}$ for the mutant and WT, respectively; Fig. 6, $E$ and $F$ ). These data indicate that S1589 phosphorylation does not appreciably alter the binding surface of R8, but does have a potentially significant change in binding of KANK to R7.

The stability and positioning of the R7 and R8 domains are maintained by an extensive network of hydrogen bonds between the linkers connecting the two domains forming a two-stranded, antiparallel ß-sheet-like structure (38). As S1589 is located close to the linker between R7 and R8, it was conceivable that the mechanosensitivity of this region may be altered by CDK1-dependent phosphorylation. To test whether posttranslational modification (PTM) of S1589 alters the mechanical stability of the domains, we used single-molecule unfolding experiments using magnetic tweezers (Fig. 7A). Our previous study of the mechanical response of talin showed that, when exposed to mechanical force, the R7R8 double domain unfolds cooperatively with a single unfolding step of $\sim 80 \mathrm{~nm}$ at $\sim 15 \mathrm{pN}$ force at a force loading rate of $\sim 3.4 \mathrm{pN} \mathrm{s}^{-1}$ (43). To further characterize the mechanical properties of R7R8, single-molecule unfolding experiments were conducted for an R7R8 construct at loading rates of $1.0 \pm 0.1$ and $5.0 \pm$ $0.5 \mathrm{pN} \mathrm{s}^{-1}$. Consistent with our previous report (43), a cooperative unfolding event was observed indicated by a single height-jump step of $\sim 70 \mathrm{~nm}$ at a force of $\sim 14 \mathrm{pN}$ (Fig. $7 B$ ). The normalized unfolding force distributions of R7R8 at force loading rates of $1 \pm 0.1 \mathrm{pN} \mathrm{s}^{-1}$ and $5 \pm 0.5 \mathrm{pN} \mathrm{s}^{-1}$ peaked at $13.3 \pm 1.6 \mathrm{pN}$ and $14.5 \pm 1.9 \mathrm{pN}$, respectively. Next, similar force-increase scans were performed with a single-molecule construct containing R7 alone (Fig. $7 \mathrm{C}$ ). In this case, the unfolding forces of the R7 domain were $10.1 \pm 1.9 \mathrm{pN}$ and $11.2 \pm 1.1 \mathrm{pN}$ for $1 \pm 0.1 \mathrm{pN} \mathrm{s}^{-1}$ and $5 \pm 0.5 \mathrm{pN} \mathrm{s}^{-1}$, respectively (Fig. $7 C$ ), demonstrating that the $\mathrm{R} 7$ domain is mechanically weaker than R7R8. As it has already been demonstrated that R8 is mechanically weak $(43,44)$, these findings indicate that the interdomain interaction between R7 and R8 is mutually stabilizing.
Next, to investigate how phosphorylation might affect the mechanical stability of R7R8, a phosphomimetic singlemolecule construct of R7R8 containing S1589D (referred as $R 7 R 8^{\mathrm{S} 1589 \mathrm{D}}$ ) was generated. The unfolding force of $\mathrm{R} 7 \mathrm{R} 8^{\mathrm{S} 1589 \mathrm{D}}$ peaked at $9.7 \pm 1.5 \mathrm{pN}$ and $10.0 \pm 1.5 \mathrm{pN}$ for $1 \pm 0.1 \mathrm{pN} \mathrm{s}^{-1}$ and $5 \pm 0.5 \mathrm{pN} \mathrm{s}^{-1}$, respectively, and was significantly reduced compared with WT R7R8 (Fig. 7D). Furthermore, R7R8 ${ }^{\text {S1589D }}$ and R7 had similar mechanical stabilities. These results demonstrate that phosphorylation of S1589 weakens the mechanical stability of this region likely by disrupting the interdomain connection of R7 and R8.

\section{Discussion}

Much of our current understanding of cell cycle regulation stems from studies on unicellular organisms, and less is known about the mechanisms coordinating cell division in the ECMcontaining tissues of multicellular organisms. Here, our principal discovery is that there is a direct binding interaction between the master cell cycle regulator, CDK1, and talin, a large mechanosensitive, actin-binding protein that plays a key role in regulating integrin-mediated cell adhesion to ECMs. We have employed biochemical and structural approaches to define the binding mechanism and demonstrate that a helical, talin-binding LD motif in CDK1 engages the talin rod R8 helical bundle. A CDK1-2A mutation, which disrupts the LD motif, impedes the assembly of IACs. Talin also contains a functional consensus CDK1 phosphorylation motif centered on S1589, which regulates the mechanical responsiveness of the region, and thereby potentially alters downstream mechanotransduction pathways. Phosphorylation of talin S1589 has been detected in multiple large-scale phosphoproteomic screens (45-47). We hypothesize that CDK1 binding to the talin scaffold could be a driver of the major morphological changes in adhesion seen during cell cycle progression and division and that this constitutes an evolutionary adaptation of the cell cycle that is fundamental to multicellularity.

Although we demonstrate that the talin-CDK1 interaction is required for CDK1-dependent regulation of IACs during the cell cycle, a more detailed understanding of the mechanisms underlying this effect remains to be elucidated. For example, the talin-CDK1 interaction might regulate phosphorylation of multiple adhesome components, thereby contributing to IAC dynamics and downstream signaling pathways. The talin R8 domain is a nexus for multiple binding interactions; thus, in addition to CDK1, it binds DLC1 $(32,48), \operatorname{RIAM}(17,49)$, and paxillin (32), which modulate various aspects of cell spreading and migration, raising the possibility that competing interactions might provide a novel regulatory axis. This is supported by the observation that deletion of R8 from talin results in an increase in adhesion area, suggesting that additional binding interactions with $\mathrm{R} 8$ are important in regulating IAC dynamics. The unique structure of the R7R8 region, in which the R8 helical bundle is inserted into the R7 helical bundle, means that R8 is shielded from force, unfolding only when R7 unfolds at $\sim 14 \mathrm{pN}$ applied force $(43,44)$. R8 therefore retains its ability to form helical addition interactions with LD-motifcontaining proteins even when flanking talin domains have 
A

\section{Talin1 R7R8}

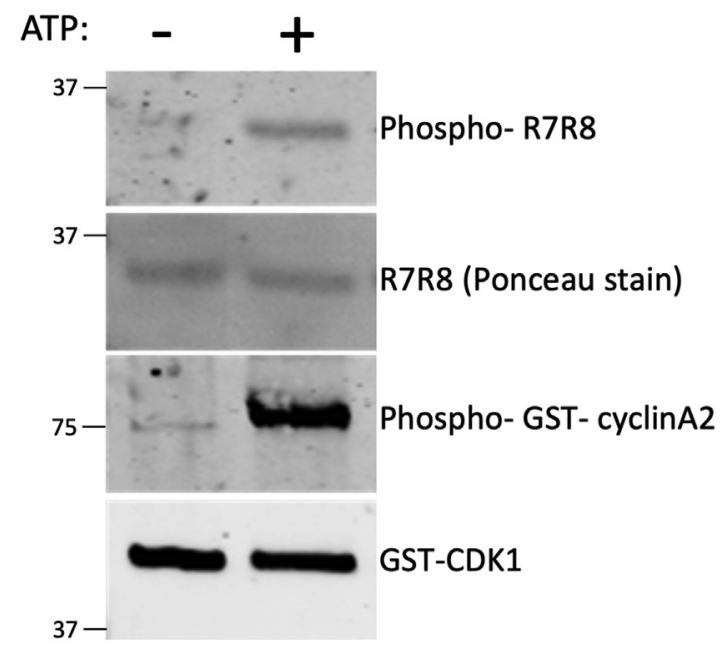

E

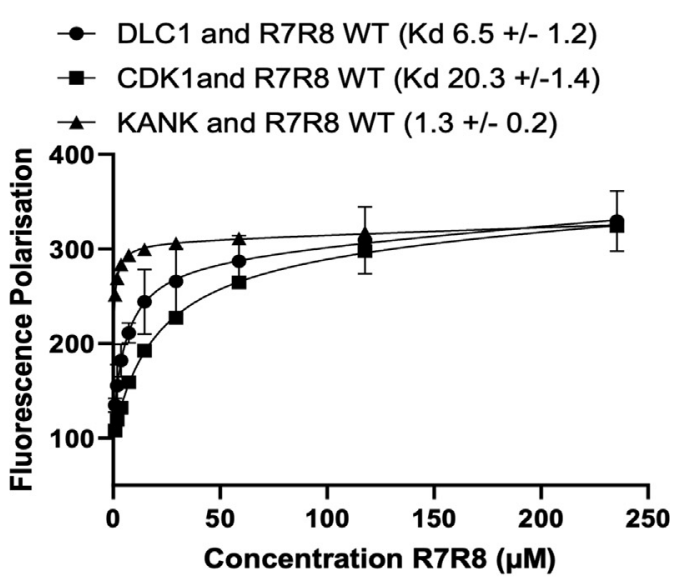

$\mathbf{F}$

$\rightarrow$ DLC1 and R7R8 S1589D (Kd 4.2 +/-0.1)

$\rightarrow$ CDK1 and R7R8 S1589D (Kd $24.3+/-1.6)$

$\neq$ KANK and R7R8 S1589D (Kd $4.4+/-0.05)$

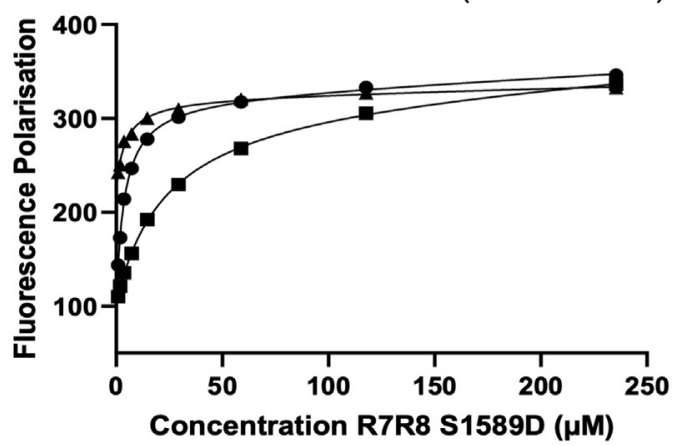

B

C

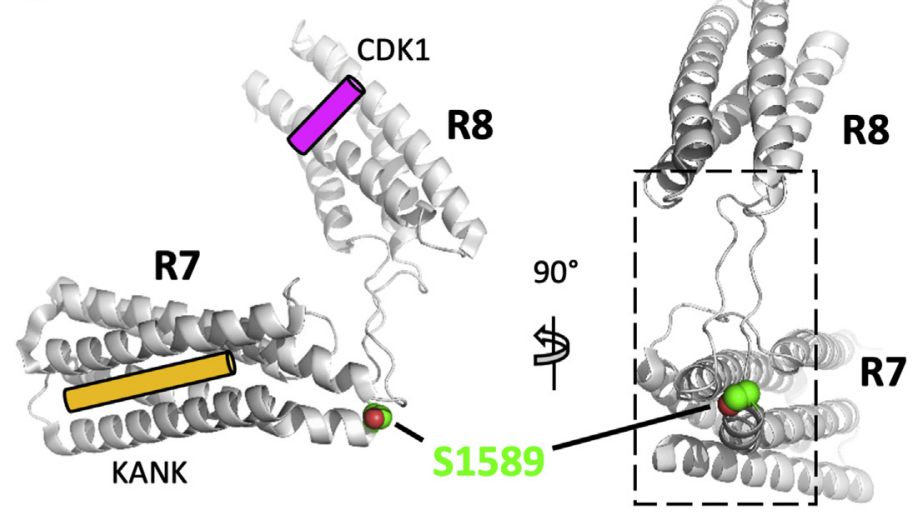

D
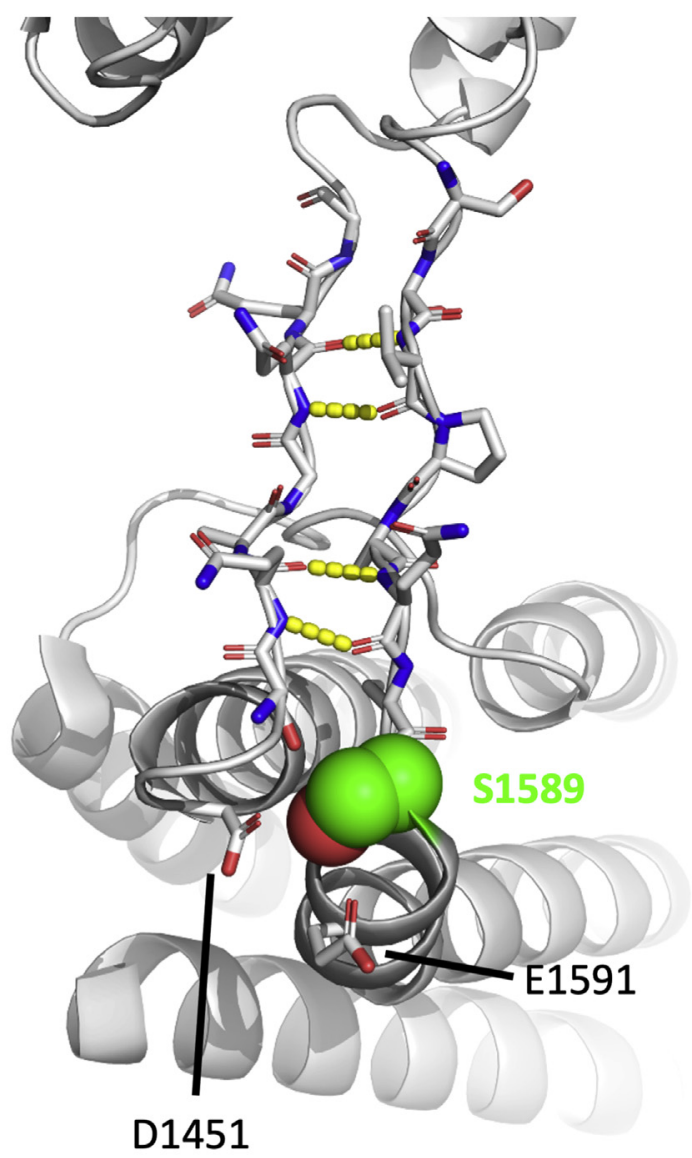

Figure 6. CDK1-cyclin A2 phosphorylates talin-1. A, western blotting of talin-1 R7R8 phosphorylation by purified CDK1-cyclin A2 in the presence of ATP. $B$, sequence of the phosphorylated Talin-1 peptide identified by the MS, the SP motif that contains the phosphorylation site at S1589 is highlighted. $C$, talin1 R7R8 structure with the phosphorylation site, S1589, highlighted in green. The binding sites for KANK on R7 and CDK1 on R8 are highlighted. D, region of the structure highlighted by the dotted region in (C). The linker between the R7 and R8 domains forms a two-stranded antiparallel B-sheet-like structure mediated by a hydrogen bonding network (dashed yellow lines). The location of the S1589 residue (green spheres) relative to the acidic side chains of D1451 and E1591. E and F, binding of BODIPY-TMR labeled CDK1 206-223C, DLC1 465-489C, and KANK1 30-60C peptides to talin-1 R7R8 (1357-1653), (E) WT and $(F)$ S1589D. Binding affinities were measured by fluorescence polarization. Dissociation constants $\pm S E(\mu M)$ for the interactions are indicated. 


\section{A direct interaction between talin and CDK1}

A

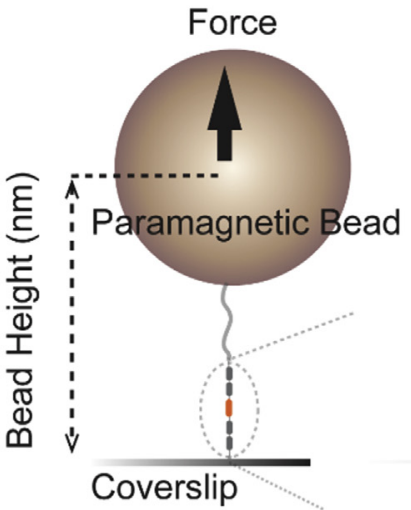

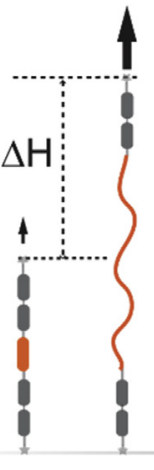

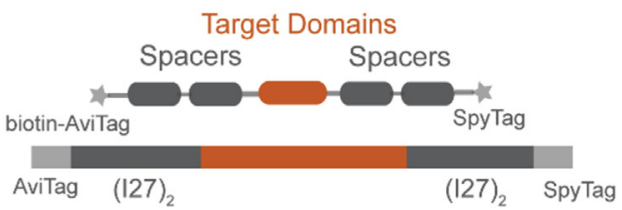

Talin R7R8 (1361-1658)

Talin R7 (1361-1462, 1578-1658)

Talin R7R8 ${ }^{\text {S1589D }}$ (1361-1658, S1589D)

B

R7R8 (1361-1658)
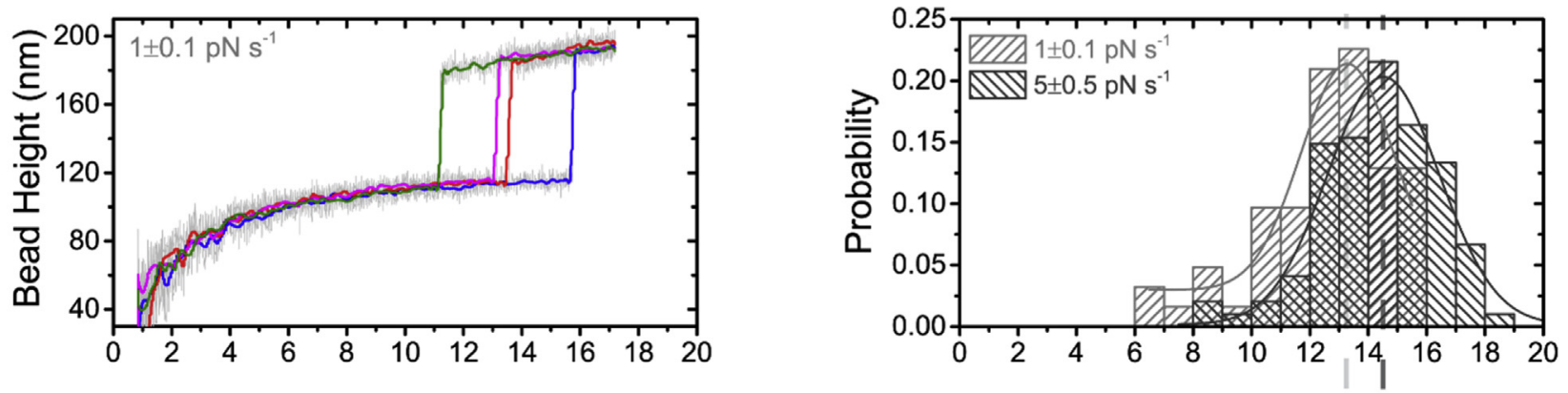

C

R7 (1361-1462, 1578-1658)
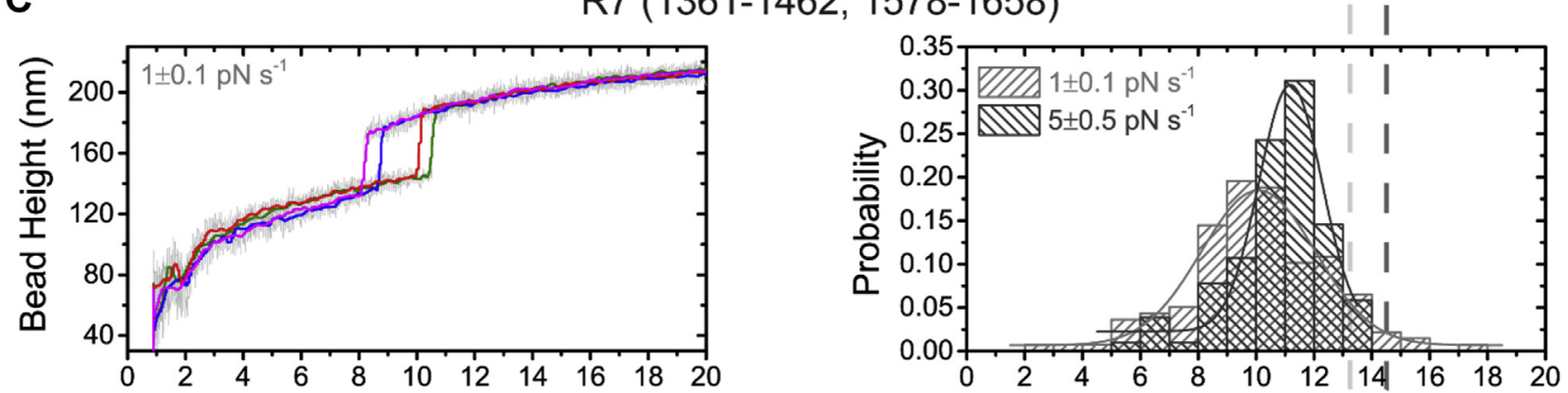

D R7R8 ${ }^{S 1589 D}$ (1361-1658, S1589D)
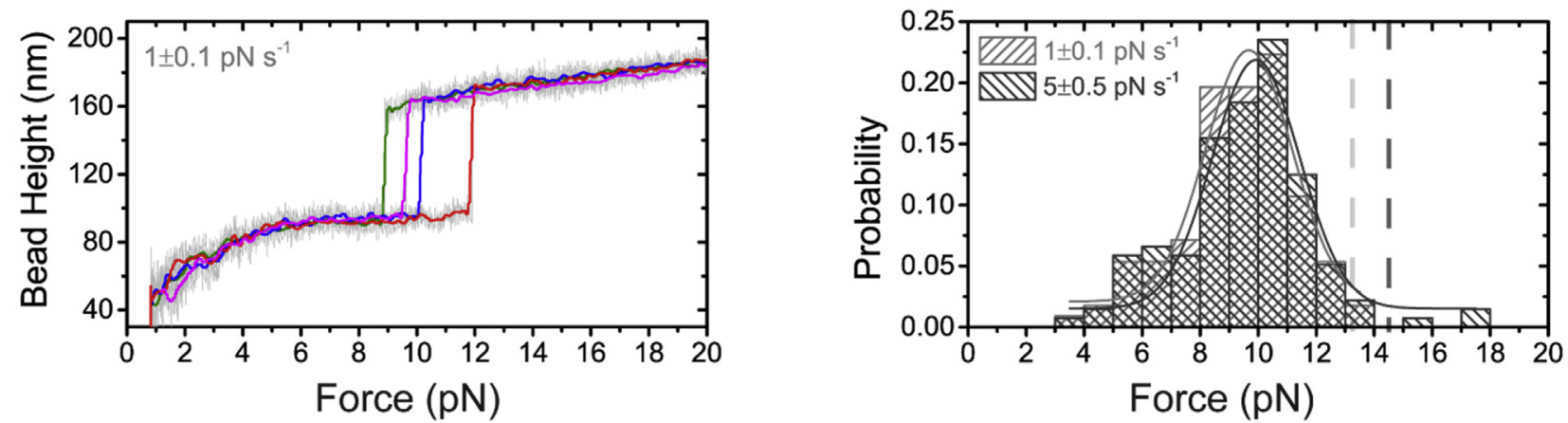

Figure 7. R7R8 module is mechanically stabilized by R7-R8 interdomain interaction. $A$, schematic of single-molecule stretching experiments where a single protein tether, coupled between a paramagnetic bead and a surface, is stretched under force. $B$, Left panel, typical force-bead height curves of the R7R8 construct during force-increase scans at a loading rate of $1 \mathrm{pN} \mathrm{s}^{-1}$. Each colored line indicates one independent force-increase scan, smoothed (10-point fast Fourier transform) from raw data (gray). Right panel, the normalized unfolding force distributions of R7R8 complex during force-increase scans at $1 \mathrm{pN} \mathrm{s}^{-1}$ and $5 \mathrm{pN} \mathrm{s}^{-1}$. The data points obtained for analysis are $\mathrm{N}=62$ and $\mathrm{N}=195$, respectively. The curves are Gaussian fitting of the distribution with peaks at $13.3 \pm 1.6 \mathrm{pN}$ and $14.5 \pm 1.9 \mathrm{pN}$, respectively. C, Left panel, typical force-bead height curves of R7 during force-increase scans at a loading rate of $1 \mathrm{pN} \mathrm{s}^{-1}$. Right panel, the normalized unfolding force distributions of R7 domain during force-increase scans at $1 \mathrm{pN} \mathrm{s}$ and $5 \mathrm{pN} \mathrm{s}$. The data points obtained for analysis are $\mathrm{N}=138\left(1 \mathrm{pN} \mathrm{s}^{-1}\right)$ and $\mathrm{N}=103\left(5 \mathrm{pN} \mathrm{s}^{-1}\right)$, respectively. The curves are Gaussian fitting of the distribution with peaks at $10.1 \pm$ $1.9 \mathrm{pN}$ and $11.2 \pm 1.1 \mathrm{pN}$, respectively. $D$, Left panel, typical force-bead height curves of the R7R8 ${ }^{\mathrm{S1598D}}$ construct during force-increase scans at a loading rate of $1 \mathrm{pN} \mathrm{s}^{-1}$. Right panel, the normalized unfolding force distributions of R7R8 ${ }^{\mathrm{S} 1598 \mathrm{D}}$ complex during force-increase scans at $1 \mathrm{pN} \mathrm{s}^{-1}$ and $5 \mathrm{pN} \mathrm{s}^{-1}$. The data points obtained for analysis are $\mathrm{N}=112\left(1 \mathrm{pN} \mathrm{s}^{-1}\right)$ and $\mathrm{N}=136\left(5 \mathrm{pN} \mathrm{s}^{-1}\right)$, respectively. The curves are Gaussian fitting of the distribution with peaks at $9.7 \pm 1.5 \mathrm{pN}$ and $10.0 \pm 1.5 \mathrm{pN}$, respectively. The light gray and the dark gray dashed lines indicate the corresponding peak force values for R7R8 at $1 \mathrm{pN} \mathrm{s}^{-1}$ and $5 \mathrm{pN} \mathrm{s}^{-1}$, respectively. 


\section{A direct interaction between talin and CDK1}

unfolded under the forces exerted at sites of adhesion. The R7R8 region also provides linkages between IACs and the cytoskeleton, and it connects to both the actin and microtubule networks (Fig. 8). Specifically, the R7 domain binds the KANK family of proteins $(34,50)$, which link to the cortical microtubule stabilizing complex, and the R8 domain forms part of the actin-binding site 2 (ABS2) that makes strong, tension-bearing linkages to the actin cytoskeleton $(23,35)$. The R7R8 domains are stabilized by a ladder of hydrogen bonds between the linkers adjoining the two domains (38), which makes the double domain one of the more stable regions in the group III (15-21 pN) of talin rod domains (43). The S1589D phosphomimetic R7R8 mutant is more susceptible to force and unfolds at $\sim 10 \mathrm{pN}$. This raises the possibility that CDK1 binding to, and phosphorylation of, the R7R8 region might regulate the association of talin with other IAC components and the cytoskeleton. The accessibility of the VBS in R8 has recently been shown to facilitate maturation of nascent adhesions (51), suggesting that phosphorylation of S1589 during the cell cycle might also regulate adhesion dynamics by controlling the availability of this helix.

The talin-binding site on CDK1 also binds to the CKS proteins that regulate CDK1 function (41). Therefore, talin and CKS interactions with CDK1 should be mutually exclusive. It is possible that the part of the CDK1 catalytic domain that binds to talin and CKS is a CDK1-targetting domain, and its interactions with various proteins relocate CDK1 to cellular compartments where it can exert its effects. In addition,

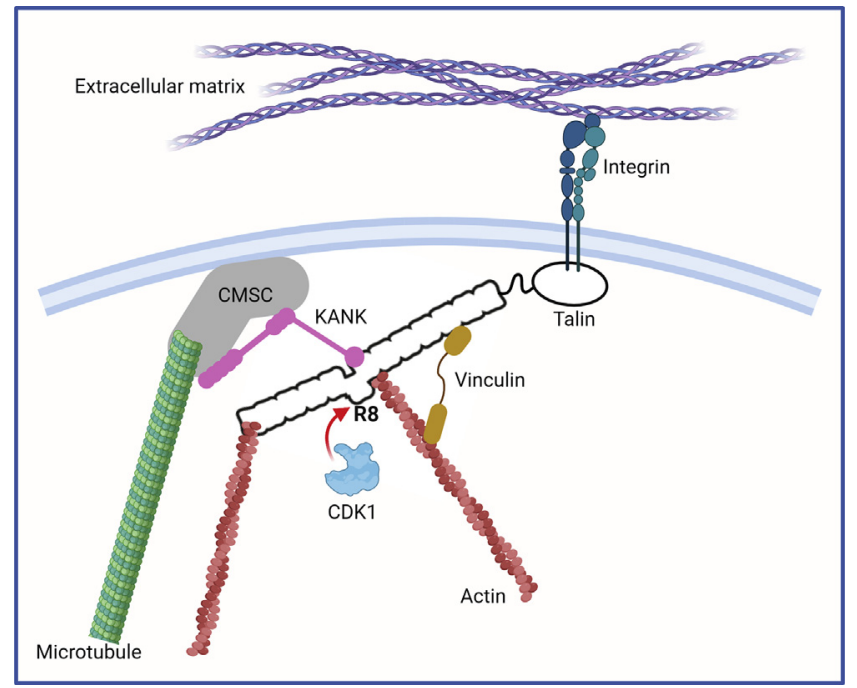

Figure 8. A cartoon to show how CDK1 regulation of talin mechanical response might orchestrate global rearrangements of the cells cytoskeleton. Talin (white) acts as a Mechanosensitive Signaling Hub that coordinates multiple cytoskeletal connections including microtubules (green), mediated via KANK (pink) and the cortical microtubule stabilizing complex (CMSC; gray) and actin (red), both directly and indirectly via vinculin (orange). The cell signaling of each integrin adhesion complex will be dependent on the conformational patterns of the talin binary switch domains and the cytoskeletal connections. The R7R8 region of talin serves as a nexus between the integrin adhesion complexes, microtubules, and actin filaments. CDK1 (blue) binding to, phosphorylating, and altering the mechanical response of the R7R8 domains has the potential to alter these cytoskeletal linkages, which might trigger global cytoskeletal rearrangement. mutating the CDK1 LD motif leads to a loss of CDK1 phosphorylation at T161, suggesting that this motif plays a key role in upstream regulation of CDK1 function. Therefore, investigating how binding partners of CDK1-WT and CDK1-2A differ could elucidate key CDK1 regulatory mechanisms. Binding of CDK1 to cyclin A requires prior phosphorylation of T161, whereas binding of CDK1 to cyclin B occurs without this phosphorylation (52), and we demonstrate that CDK1-2A is still able to associate effectively with cyclin $\mathrm{B}$, but is unable to complex with cyclin A. Thus, the CDK1-2A mutant may prove to be a useful tool for distinguishing the different roles of CDK1-cyclin A and CDK1-cyclin B during cell cycle progression. In this context, expression of CDK1-2A leads to a reduction in IACs and loss of IAC growth during $S$ phase, processes that we have previously attributed to CDK1-cyclin A, implying its utility in elucidating the mechanisms by which CDK1-cyclin A modifies IACs and the cytoskeleton.

The observation that CDK1-dependent phosphorylation of talin at S1589 alters the mechanical sensitivity of R7R8 has implications for the role of talin as a mechanosensitive signaling hub (27). This paradigm is based on the concept that the talin scaffold that connects integrins to the cytoskeleton can adopt many different conformations as a result of its binary switch patterns. These binary switches enable the cell to alter its behavior in response to signaling, but also based on prior events, imbuing the cell with mechanical memory (53). The highly reproducible response of talin to mechanical force is due to each of the talin switch domains having different mechanical responses to force (43) and recruiting different signaling molecules as a function of force. The phosphorylation of S1589 by CDK1 may therefore alter the order that the talin switch domains unfold (Fig. 7). As further speculation, the concept of mechanical computation of the cell (53), in which the entire cytoskeletal architecture functions as a computational assembly, predicts that cell architecture is dictated by the signals that the cell has received and the current patterns of mechanical switches in the cells. Alteration of this pattern by talin S1589 phosphorylation might lead to global changes to mechanotransduction downstream of talin. Furthermore, other talin switch domains are also predicted to be modified by PTM (Fig. S4) (54). It may be that talin signaling, mechanotransduction via mechanical linkages, and information storage in binary switches are controlled by PTMs across many different tissues and scenarios. In this context, cell polarity is a key driver of tissue self-organization and coupling cell division to the geometry and mechanics of the cytoskeletal machinery may provide a means of regulating the polarity and organization of cells into tissues that underpins multicellularity. Prior to division, most cells are attached to an underlying ECM via IACs and/or to neighboring cells. While modulation of adhesion occurs during interphase to enable mitotic cell rounding and physical separation of daughter cells, the links between the cell cycle and cell adhesion are poorly understood. The novel interaction between talin and CDK1 identified in this report provides a framework for understanding these linkages. 


\section{A direct interaction between talin and CDK1}

Our studies demonstrate that CDK1 is able to phosphorylate talin and switch talin into a state with different mechanical properties, potentially altering the talin interactome and function in IACs. As talin is central to the downstream events emanating from integrins, its interaction with CDK1 may enable large-scale, synchronized changes to cell architecture to be enabled during cell cycle progression and other adhesionrelated processes such as cell migration. Furthermore, it is conceivable that changes in ECM stiffness sensed by talin may impact upon CDK1 activity and function, providing a direct, primordial link between mechanosensing and the induction of cell proliferation. Defining the changes in the talin and CDK1 interactomes that result from CDK1-talin binding and the knock-on consequences for adhesion and cell cycle signaling will be a priority.

\section{Experimental procedures}

\section{Antibodies and reagents}

Monoclonal antibodies used were mouse anti-paxillin (clone 349; 1:500 for immunofluorescence; BD Biosciences; 610051), mouse anti-cyclin B1 (Clone GNS3; 1:2000; Merck Millipore 05373), mouse anti-cyclin A2 (clone BF683; 1:1000, Cell Signaling Technology 4656), mouse anti-CDK1 (clone POH1; 1:1000; Cell Signaling Technology 9116), mouse anti-actin (clone AC-40; 1:2000; Sigma-Aldrich A3853), mouse anti-HA (clone 12CA5; 1:2000: Thermo Fisher MA1-12429), and rabbit anti-CDK1 pY15 (clone 10A11; 1:1000; Cell Signaling Technology 4539). Polyclonal antibodies used were rabbit anti-CDK1 (1:1000; Merck Millipore; ABE1403), and rabbit anti-CDK1 pT161 (1:1000; Cell Signaling Technology; 9114). Secondary Alexa-Fluor 680-conjugated (1:10,000; Thermo Fisher A10043) or DyLight 800-conjugated (1:10,000; Cell Signaling Technology 5257) antibodies were used for immunoblotting. Anti-mouse and anti-rabbit Alexa-Fluor 680-conjugated light-chain-specific secondary antibodies were used (1:5000) for immunoblotting immunoprecipitations (Jackson ImmunoResearch; 115-625-174 and 211-622-171). Anti-mouse and anti-rabbit Alexa-Fluor 488and 594-conjugated secondary antibodies (1:500) were used for immunofluorescence (all from Thermo Fisher). Thymidine and RO-3306 were purchased from Sigma-Aldrich. The cdc2-HA plasmid was obtained from Addgene (\#188818).

\section{Protein purification}

Expression constructs of talin were prepared using mouse talin-1 DNA cloned into the expression vector pET151-TOPO, expressed in E.coli BL21(DE3) Star and cultured in either minimal media for NMR samples or LB for nonlabeled samples. Proteins were purified using nickel affinity chromatography and the His-tag removed by TEV protease cleavage (55). The protein was then further purified using ion exchange chromatography. The protein constructs used were mouse talin-1 R1-R3 (residues 482-911), R4-R8 (residues 913-1653), R7R8 (residues 1357-1653), R8 (residues 1461-1580), R9-R10 (residues 1655-1973), R10 (residues 1815-1973), R11-R12 (residues 1974-2294), R13-DD (residues 2300-254), and mouse talin-2 R7R8 (residues 1360-1656).

\section{Fluorescence polarization}

The following peptides with a terminal cysteine residue were synthesized by GLBiochem (Shanghai): CDK1(206-223) GDSEIDQLFRIFRALGTP-C, CDK1-2A(206-223) GDSEAA QLFRIFRALGTP-C, DLC1(465-489) IFPELDDILYHVKG MQRIVNQWSEK-C, and KANK1(30-60) PYFVETPYGFQL DLDFVKYVDDIQKGNTIKK-C (34). BODIPY-TMR coupled peptides dissolved in PBS $(137 \mathrm{mM} \mathrm{NaCl}, 27 \mathrm{mM} \mathrm{KCl}, 100 \mathrm{mM}$ $\mathrm{Na}_{2} \mathrm{HPO}_{4}, 18 \mathrm{mM} \mathrm{KH} \mathrm{PO}_{4}, \mathrm{pH}$ 7.4), $5 \mathrm{mM} \mathrm{TCEP}$, and 0.05\% $(\mathrm{v} / \mathrm{v})$ Triton X-100 were used at a final concentration of $0.5 \mu \mathrm{M}$. Uncoupled dye was removed using a PD-10 gel filtration column (GE Healthcare). Fluorescence polarization measurements were recorded on a BMGLabTech CLARIOstar plate reader and analyzed using GraphPad Prism (version 6.07). Kd values were calculated by nonlinear curve fitting using a one site total and nonspecific binding model.

\section{NMR spectroscopy}

NMR samples were prepared in $50 \mathrm{mM} \mathrm{NaCl}, 15 \mathrm{mM}$ $\mathrm{NaH}_{2} \mathrm{PO}_{4}, 6 \mathrm{mM} \mathrm{Na} \mathrm{HPO}_{4}, 2 \mathrm{mM}$ DTT, pH 6.5, 5\% (v/v) $\mathrm{D}_{2} \mathrm{O}$. All data were collected at a temperature of $298 \mathrm{~K}$ on a Bruker Avance III $600 \mathrm{MHz}$ NMR spectrometer equipped with CryoProbe. The spectra were processed using Topspin (Bruker) and analyzed using CCPN Analysis (56). Backbone resonance assignments of talin-1 R8 residues 1461 to 1580 were assigned previously (BMRB ID:19339 (32)).

\section{$X$-ray crystallography}

Talin-1 R7R8 was concentrated to $300 \mu \mathrm{M}$ in $50 \mathrm{mM} \mathrm{NaCl}$, $3 \mathrm{mM}$ DTT, $20 \mathrm{mM}$ Tris, $\mathrm{pH}$ 7.4, and incubated with CDK1 peptide in an 8:1 $\mathrm{M}$ excess. Sitting-drop sparse matrix crystallization screening was performed using a Mosquito solution handling robot (TTP Labtech) with $400 \mathrm{nl}$ drops and a 1:1 precipitate:precipitant ratio. Crystals formed in $20 \%$ Isopropanol, 20\% PEG4K, $0.1 \mathrm{M} \mathrm{Na}$ citrate, $\mathrm{pH} 5.6$ at $4{ }^{\circ} \mathrm{C}$ in 3 to 4 weeks. Crystals were vitrified in mother liquor containing $25 \%(\mathrm{v} / \mathrm{v})$ glycerol in liquid nitrogen. Diffraction data were collected on I24 (Diamond) and indexed and integrated using the Xia2 3dii pipeline in space group P212121. The structure was solved using molecular replacement using PHASER (57) with the search model 2X0C and two copies of R7R8 present in the asymmetric unit. Post molecular replacement electron density for the CDK1 peptide was visible in the $\mathrm{F}_{0}-\mathrm{F}_{\mathrm{C}}$ difference map, allowing the unambiguous assignment of all side chain positions. The structure was refined using Phenix 1.17 (58) and modeled using COOT (59). Data were refined using isotropic B-factors and prior to deposition with a round of weight optimization of both the stereochemical and B-factor weights. Data reduction and refinement statistics are shown in Table S3.

\section{Cell culture, synchronization, and transfection}

U2OS cells (European Collection of Cell Cultures 92022711; Sigma-Aldrich) were maintained in DMEM (Sigma-Aldrich) supplemented with 10\% (v/v) FCS (Lonza), 1\% (v/v) penicillin/ streptomycin, and $2 \mathrm{mM}$ L-glutamine at $37{ }^{\circ} \mathrm{C}, 5 \%(\mathrm{v} / \mathrm{v})$ 


\section{A direct interaction between talin and CDK1}

$\mathrm{CO}_{2}$. For steady-state analysis of adhesion complexes in asynchronous cells, cells were cultured on glass coverslips for $48 \mathrm{~h}$ and then treated with indicated compounds for $1 \mathrm{~h}$. U2OS cells were synchronized by using a double-thymidine block protocol. Cells were plated, and after $24 \mathrm{~h}$ of growth, thymidine was added to a final concentration of $2 \mathrm{mM}$, and the cells were incubated for $16 \mathrm{~h}$. Cells were then washed twice with PBS and allowed to grow for $8 \mathrm{~h}$ in fresh DMEM. Thymidine was then added to a final concentration of $2 \mathrm{mM}$ for an additional $16 \mathrm{~h}$ before cells were washed twice with PBS and released into DMEM. U2OS cells were transfected with DNA constructs by using Lipofectamine 3000 reagent (SigmaAldrich) and siRNAs by using oligofectamine (Sigma-Aldrich) according to the manufacturer's instructions. Knockdown of CDK1 was performed by using SMARTpool reagents (L003224-00-0005; GE Healthcare), and ON-TARGETplus nontargeting siRNA (GE Healthcare) was used as a negative control.

\section{GFP-trap and mass spectrometry analysis}

U2OS cells stably expressing talin-1-GFP or GFP were first generated via transient transfection using Lipofectamine 2000 (Thermo Fisher Scientific) and selected using regular media supplemented with $500 \mu \mathrm{g} / \mathrm{ml}$ of G418. Cells were then plated on fibronectin for $2 \mathrm{~h}$, washed with PBS, and lysed in CSK buffer $[0.5 \%(\mathrm{w} / \mathrm{v})$ Triton X-100, $10 \mathrm{mM}$ Pipes, $\mathrm{pH} 6.8$, $150 \mathrm{mM} \mathrm{NaCl}, 150 \mathrm{mM}$ sucrose, $3 \mathrm{mM} \mathrm{MgCl}, 10 \mathrm{mg} / \mathrm{ml}$ leupeptin, $10 \mathrm{mg} / \mathrm{ml}$ aprotinin, $0.5 \mathrm{mM}$ 4-(2-aminoethyl) benzenesulfonyl fluoride hydrochloride, $\left.2 \mathrm{mM} \mathrm{Na}_{3} \mathrm{VO}_{4}\right]$. Lysates were incubated with GFP-Trap agarose beads (Chromotek) for $1 \mathrm{~h}$ at $4{ }^{\circ} \mathrm{C}$. Complexes bound to the beads were washed three times with ice-cold lysis buffer and eluted in Laemmli reducing sample buffer. Protein samples were separated by SDS-PAGE and following staining with InstantBlue (Expedeon), gel lanes were sliced into ten $2-\mathrm{mm}$ bands and subjected to in-gel trypsin digestion (60). Samples were analyzed by LC-MS/MS using an UltiMate 3000 Rapid Separation LC (RSLC, Dionex Corporation) coupled to an Orbitrap Elite (Thermo Fisher Scientific) mass spectrometer. Peptide mixtures were separated using a gradient from $92 \%$ A $(0.1 \%$ FA in water) and $8 \% \mathrm{~B}(0.1 \% \mathrm{FA}$ in acetonitrile) to $33 \% \mathrm{~B}$, in $44 \mathrm{~min}$ at $300 \mathrm{nl} \cdot \mathrm{min}^{-1}$, using a $75 \mathrm{~mm} \times 250 \mu \mathrm{m}$ i.d. 1.7 MBEH C18, analytical column (Waters). Peptides were automatically selected for fragmentation by data-dependent analysis. Tandem mass spectra were extracted using extract_msn (Thermo Fisher Scientific) executed in Mascot Daemon (Matrix Science). Peak list files were searched against the SwissProt human database (version 3.70, May 2013). Carbamidomethylation of cysteine was set as a fixed modification, and oxidation of methionine was allowed as a variable modification. Only tryptic peptides were considered, with up to one missed cleavage permitted. Monoisotopic precursor mass values were used, and only doubly and triply charged precursor ions were considered. Mass tolerance for precursor and fragment ions was $0.5 \mathrm{Da}$. Data were validated in Scaffold using the following threshold: at least $80 \%$ probability at the peptide level, at least $99 \%$ probability at the protein level, and at least two unique peptides. Relative protein abundance was calculated using the unweighted spectral count of a given protein normalized to the total number of spectra observed in the entire sample and to the molecular weight of that protein (normalized spectral count). SAINT and FC_B scores were calculated using the Resource for Evaluation of Protein Interaction Networks (REPRINT) online tool (https://reprintapms.org/).

\section{Proximity biotinylation, purification of biotinylated proteins, and mass spectrometry analysis}

U2OS cells were seeded onto plastic tissue culture plates overnight, then transfected with BirA* empty vector or BirA*$\mathrm{CDK} 1$, and incubated for a further $16 \mathrm{~h}$. Transfected cells were then incubated in medium with $50 \mu \mathrm{M}$ biotin for $24 \mathrm{~h}$. Biotinylated proteins were affinity purified following a protocol adapted from Roux et al. $(61,62)$. Three 10 -cm plates of cells were washed three times in PBS, and cells were lysed with $400 \mu \mathrm{l}$ lysis buffer $(50 \mathrm{mM}$ Tris- $\mathrm{HCl}, \mathrm{pH} 7.4,250 \mathrm{mM} \mathrm{NaCl}$, $0.1 \%$ [w/v] SDS, $0.5 \mathrm{mM} \mathrm{DTT}$, and $1 \times$ cOmplete Protease Inhibitor Cocktail) at RT. $120 \mu \mathrm{l} 20 \%(\mathrm{v} / \mathrm{v})$ Triton X-100 was added, and cell lysates were maintained at $4{ }^{\circ} \mathrm{C}$. DNA was sheared by passing cell lysates through a $19 \mathrm{G}$ needle four times before $360 \mu \mathrm{l}$ chilled $50 \mathrm{mM}$ Tris- $\mathrm{HCl}, \mathrm{pH}$ 7.4, was added, and then passing through a 27G needle four times. Cell lysates were centrifuged at full speed for $10 \mathrm{~min}$ at $4{ }^{\circ} \mathrm{C}$, and supernatant was rotated with $45 \mu \mathrm{l}$ MagReSyn streptavidin beads (ReSyn Biosciences) at $4{ }^{\circ} \mathrm{C}$ overnight. Beads were washed twice with $500 \mu \mathrm{l}$ wash buffer $1(10 \%$ [w/v] SDS), once with $500 \mu \mathrm{l}$ wash buffer $2(0.1 \%[\mathrm{w} / \mathrm{v}]$ deoxycholic acid, $1 \%[\mathrm{w} / \mathrm{v}]$ Triton X-100, $1 \mathrm{mM}$ EDTA, $500 \mathrm{mM} \mathrm{NaCl}$, and $50 \mathrm{mM}$ HEPES), and once with $500 \mu \mathrm{l}$ wash buffer $3(0.5 \%[\mathrm{w} / \mathrm{v}]$ deoxycholic acid, 0.5\% [w/v] NP-40, 1 mM EDTA, and $10 \mathrm{mM}$ Tris $/ \mathrm{HCl}, \mathrm{pH}$ 7.4). Proteins were eluted in $40 \mu \mathrm{l}$ of $2 \times$ reducing sample buffer with $100 \mu \mathrm{M}$ biotin for $10 \mathrm{~min}$ at $70{ }^{\circ} \mathrm{C}$. Eluted proteins were briefly subjected to SDS-PAGE (3 min at $200 \mathrm{~V}, 4-12 \%$ Bis-Tris gel, Life Technologies) and stained with InstantBlue Coomassie protein stain before being washed with $\mathrm{dd}_{2} \mathrm{O}$ overnight at $4{ }^{\circ} \mathrm{C}$. Bands were excised and transferred to wells in a perforated 96-well plate, and in-gel tryptic digestion was performed as previously described (60). Peptides were desalted using $1 \mathrm{mg}$ POROS Oligo R3 beads (Thermo Fisher Scientific). Beads were washed with $50 \mu \mathrm{l} \mathrm{0.1 \%}$ $(\mathrm{v} / \mathrm{v})$ formic acid (FA) before the peptide solution was added. Beads were washed twice with $100 \mu \mathrm{l} 0.1 \%(\mathrm{v} / \mathrm{v}) \mathrm{FA}$, and peptides were eluted twice with $50 \mu \mathrm{l} 50 \%(\mathrm{v} / \mathrm{v})$ acetonitrile $(\mathrm{ACN})$ and $0.1 \%(\mathrm{v} / \mathrm{v})$ FA. Peptides were dried using a vacuum centrifuge and resuspended in $11 \mu \mathrm{l} 5 \%(\mathrm{v} / \mathrm{v}) \mathrm{ACN}$ and $0.1 \%$ (v/v) FA. Peptides were analyzed by liquid chromatography (LC)-tandem MS (MS/MS) using an UltiMate 3000 Rapid Separation LC (RSLC, Dionex Corporation) coupled to an Orbitrap Elite mass spectrometer (Thermo Fisher). Peptides were separated on a bridged ethyl hybrid $\mathrm{C} 18$ analytical column $(250 \mathrm{~mm} \times 75 \mu \mathrm{m}$ inner diameter, $1.7 \mu \mathrm{m}$ particle size, Waters) over a $1 \mathrm{~h}$ gradient from 8 to $33 \%$ (v/v) ACN 


\section{A direct interaction between talin and CDK1}

in $0.1 \%(\mathrm{v} / \mathrm{v})$ FA. LC-MS/MS analyses were operated in data-dependent mode to automatically select peptides for fragmentation by collision-induced dissociation (CID). Quantification was performed using Progenesis LC-MS software (Progenesis QI, Nonlinear Dynamics; http://www.nonlinear. $\mathrm{com} /$ progenesis/qi-for-proteomics/). In brief, automatic alignment was used, and the resulting aggregate spectrum filtered to include $+1,+2$, and +3 charge states only. A.mgf file representing the aggregate spectrum was exported and searched using Mascot Server Version 2.5.1 (tryptic peptides only, monoisotopic $\mathrm{m} / \mathrm{z}$ precursors, $2+3+$ and $4+$ charge states, one missed cleavage, fixed modification: carbamidomethyl [C]; variable modifications: biotinylation [B], oxidation [M]; peptide tolerance: $\pm 5 \mathrm{ppm}$; MS/MS tolerance: $\pm 0.5 \mathrm{Da}$, searched against the UniProtKB human database 2018_01 (January 31, 2018) consisting of 108,184,003 entries (UniProtKB/Swiss-Prot: 556,568 entries and UniProtKB/TrEMBL: $107,627,435$ entries)), and the resulting.xml file was reimported without filtering to assign peptides to features. The estimated protein false discovery rate was $0.5 \%$ calculated using Scaffold (version 4.4.7; Proteome Software) using a threshold of identification of at least $90 \%$ probability at the peptide level, assignment of at least two unique peptides, and at least $95 \%$ probability at the protein level. Three separate experiments were performed, and abundance values for proteins identified in the analysis using three or more peptides for quantification by Progenesis were used to determine which proteins were enriched over twofold in cells expressing BirA*CDK1 relative to cells expressing BirA*-empty vector control.

\section{Immunoprecipitation}

U2OS cells transfected with GFP-tagged talin-1, GFP-tagged $\Delta \mathrm{R} 8$ talin-1, or GFP alone or synchronized in G2 $9 \mathrm{~h}$ after thymidine arrest (two 15-cm-diameter dishes per condition) were lysed (500 $\mu \mathrm{l}$ per dish) in modified CSK buffer $(150 \mathrm{mM}$ $\mathrm{NaCl}, 25 \mathrm{mM}$ Tris-HCl, pH 7.4, 1 mM EDTA, 1\% (v/v) NP40), protease inhibitors (11836145001; Roche), and PhosStop reagent (Roche). Lysates were passed five times through a narrow-bore tip before centrifugation $(10,000 \mathrm{~g}$ for $3 \mathrm{~min}$ at $4{ }^{\circ} \mathrm{C}$ ). After centrifugation, $20 \mu \mathrm{l}$ GFP-trap Sepharose beads (Chromotek) or immunoprecipitating mAbs (mouse anticyclin B1 clone GNS3 or mouse anti-cyclin A clone E67.1; SC53230; Santa Cruz Biotechnology, Inc, or mouse IgG; Sigma-Aldrich) were added to the lysate $(2 \mu \mathrm{g} / \mathrm{ml}$ cyclin B1 and $10 \mu \mathrm{g} / \mathrm{ml}$ cyclin A final concentration) together with protein G Sepharose $(20 \mu \mathrm{l}$ of $50 \%$ slurry bead volume; GE Healthcare) for $16 \mathrm{~h}$ at $4{ }^{\circ} \mathrm{C}$. Sepharose beads were then collected and washed two times in lysis buffer and once in distilled $\mathrm{H}_{2} \mathrm{O}$ by centrifugation ( $2800 \mathrm{~g}$ for $2 \mathrm{~min}$ ). GFPassociated or immunoprecipitated complexes were eluted $(30 \mu \mathrm{l})$ at $\mathrm{pH} 2$ for $5 \mathrm{~min}$ at $25^{\circ} \mathrm{C}$ and neutralized according to the manufacturer's instructions (88805; Thermo Fisher Scientific). Samples were then reduced at $70{ }^{\circ} \mathrm{C}$ for $5 \mathrm{~min}$ by dilution in $5 \times$ sample buffer (125 mM Tris, 10\% (w/v) SDS, $25 \%(\mathrm{v} / \mathrm{v})$ glycerol, $0.01 \%(\mathrm{w} / \mathrm{v})$ bromophenol blue, and $10 \%(\mathrm{v} /$ v) $\beta$-mercaptoethanol) and subjected to SDS-PAGE and western blotting by using the Odyssey Infrared Imaging System. To avoid detection of antibody heavy chains, light-chainspecific Alexa Fluor 680-conjugated secondary antibodies were used (1:5000).

\section{Immunofluorescence microscopy}

U2OS cells were fixed in $4 \%$ (w/v) PFA for 20 min, washed twice with PBS, and permeabilized by using $0.2 \%(\mathrm{w} / \mathrm{v})$ Triton $\mathrm{X}-100$ in PBS for 10 min. Cells were then washed with PBS and PFA quenched by incubation with $0.1 \mathrm{M}$ glycine/PBS for $30 \mathrm{~min}$. Cell were washed with PBS three times and then incubated with primary antibodies (45 min at RT) and washed with PBS containing $0.1 \%(\mathrm{w} / \mathrm{v})$ Tween-20 (PBST) and incubated for $30 \mathrm{~min}$ with the appropriate secondary antibodies and, where applicable, Alexa Fluor dye-conjugated phalloidin (Thermo Fisher Scientific). Finally, cells were washed three times with PBST and once with distilled $\mathrm{H}_{2} \mathrm{O}$ before being mounting on coverslips by using ProLong diamond antifade reagent (Thermo Fisher Scientific) and imaging. Images were acquired on an inverted confocal microscope (TCS SP5 Acousto-Optical Beam Splitter; Leica Microsystems) by using a 63× objective (HCX Plan Apochromat, NA 1.25) and Leica Confocal Software (Leica Microsystems), and image analysis was performed using ImageJ. Images were background subtracted by using rolling ball subtraction, and images of paxillin staining (mouse anti-paxillin, clone 349, BD Biosciences) or GFP-talin-1 were thresholded to define adhesion complexes. By using a size cutoff of $0.2 \mu \mathrm{m}$, the total area of adhesion complexes was determined per cell as a proportion of total cell area. Representative cells were selected based on consistency with phenotype observed across the field of view, with distinct cells present within a similar density of surrounding cells being chosen for analysis.

\section{Total internal reflection fluorescence (TIRF) microscopy}

U2OS cells stably expressing GFP-talin-1 constructs were transfected with mScarlet-CDK1 using Lipofectamine 3000 according to manufacturer's instructions. Cells were then plated onto glass-bottomed dishes (Mat-tek), cultured overnight, and fixed with $4 \%(\mathrm{w} / \mathrm{v})$ PFA for $20 \mathrm{~min}$, then washed twice with PBS. Images were collected on a Leica Infinity TIRF microscope using a $100 \times / 1.47$ HC PL Apo Corr TIRF Oil objective with $488 \mathrm{~nm}$ and $561 \mathrm{~nm}$ diode TIRF lasers (with $30 \%$ laser power and a penetration depth of $110 \mathrm{~nm}$ ) and an ORCA Flash V4 CMOS camera (Hamamatsu) with $300 \mathrm{~ms}$ exposure time and camera gain of 2 . Images were background subtracted by using rolling ball subtraction using ImageJ, and representative images were selected based on consistency with phenotype observed across the field of view.

\section{Immunoblotting}

Cells were lysed in lysis buffer $(150 \mathrm{mM} \mathrm{NaCl}, 25 \mathrm{mM}$ Tris$\mathrm{HCl}, \mathrm{pH} 7.4,1$ mM EDTA, 1\% (v/v) NP-40, 5\% (v/v) glycerol, $1 \times$ protease inhibitor cocktail [Sigma Aldrich], and $1 \times$ PhosSTOP phosphatase inhibitor cocktail [Sigma-Aldrich]). Lysates were clarified by centrifugation at $10,000 \mathrm{~g}$ for $5 \mathrm{~min}$ at $4{ }^{\circ} \mathrm{C}$. 


\section{A direct interaction between talin and CDK1}

Cell lysates were separated by SDS-PAGE (4-12\% Bis-Tris gels; Thermo Fisher Scientific) under reducing conditions and transferred to nitrocellulose membranes (Whatman). Membranes were blocked for $60 \mathrm{~min}$ at RT using 5\% (w/v) BSA in TBS (10 mM Tris- $\mathrm{HCl}, \mathrm{pH} 7.4$, and $150 \mathrm{mM} \mathrm{NaCl})$ containing $0.05 \%(\mathrm{w} / \mathrm{v})$ Tween-20 (TBST) and then probed overnight with primary antibodies diluted in $5 \%(\mathrm{w} / \mathrm{v}) \mathrm{BSA} /$ TBST at $4{ }^{\circ} \mathrm{C}$. Membranes were washed for $30 \mathrm{~min}$ by using TBST and then incubated with the appropriate fluorophoreconjugated secondary antibody diluted in $5 \%(\mathrm{w} / \mathrm{v}) \mathrm{BSA} /$ TBST for $45 \mathrm{~min}$ at $\mathrm{RT}$ in the dark. Membranes were washed for $30 \mathrm{~min}$ in the dark by using TBST and then scanned by using the Odyssey infrared imaging system (LICOR Biosciences)

\section{In vitro kinase assay}

Purified recombinant GST-tagged CDK1-cyclin A2 and $\mathrm{His}_{6}$-tagged CDK1-cyclin B1 (Invitrogen) were stored in $150 \mathrm{mM} \mathrm{NaCl}, 0.5 \mathrm{mM}$ EDTA, $0.01 \%$ (v/v) Triton X-100, $2 \mathrm{mM}$ DTT, $20 \%$ (v/v) glycerol $20 \mathrm{mM}$ Tris, pH 7.5. $30 \mathrm{ng}$ of each protein were mixed with $0.1 \mu \mathrm{g}$ of substrate (talin R7R8) and incubated in $150 \mathrm{mM} \mathrm{NaCl}, 5 \mathrm{mM}$ EDTA, $5 \mathrm{mM}$ DTT, $25 \mathrm{mM} \mathrm{MgCl}_{2}, 0.02 \%$ (v/v) Triton X-100, $1 \mathrm{mM}$ ATP, $50 \mathrm{mM}$ HEPES, pH 7.4 at $30{ }^{\circ} \mathrm{C}$ with shaking at $100 \mathrm{rpm}$ for $20 \mathrm{~min}$. The reaction was stopped by adding SDS sample buffer and boiled at $95{ }^{\circ} \mathrm{C}$ for $10 \mathrm{~min}$. A gradient SDS-PAGE 4 to $12 \%$ Bis-Tris gel (Thermo Fisher Scientific) was loaded with the entire sample and run at $200 \mathrm{~V}$ for $45 \mathrm{~min}$ in $1 \times$ SDS running buffer (NuPAGE). After western blotting, antiphosphorylated CDK substrate antibody (Cell Signaling Technology) was used to probe the reactions.

\section{Phosphorylation site analysis}

Phosphorylation sites of talin-1 R7R8 were determined using mass spectrometry. The in vitro kinase assay was carried out with the substrate talin-1 R7R8 and CDK1-cyclin A2. Reactions was carried out for $45 \mathrm{~min}$ at $30^{\circ} \mathrm{C}$ and stopped by adding SDS sample buffer and boiling for $10 \mathrm{~min}$ at $95^{\circ} \mathrm{C}$. All samples were loaded onto an SDS PAGE 4 to $12 \%$ Bis-Tris gel (Thermo Fisher Scientific) and separated by running at $200 \mathrm{~V}$ for $60 \mathrm{~min}$. Gels were stained with Instant-Blue (Expedeon) for $15 \mathrm{~min}$ and washed in water overnight at $4{ }^{\circ} \mathrm{C}$. The talin R7R8 bands were cut from the gel and processed by in-gel tryptic digestion. Peptides were analyzed by LC-MS/MS by using an UltiMate 3000 Rapid Separation LC (Dionex Corporation) coupled to an Orbitrap Elite MS (Thermo Fisher Scientific). Peptides were separated on a bridged ethyl hybrid C18 analytical column $(250 \mathrm{~mm} \times 75 \mu \mathrm{m}$ internal diameter, $1.7 \mu \mathrm{m}$ particle size; Waters) over a 45 min gradient from 8 to $33 \%(\mathrm{v} /$ $\mathrm{v})$ acetonitrile in $0.1 \%(\mathrm{v} / \mathrm{v})$ formic acid. LC-MS/MS analyses were operated in data-dependent mode to automatically select peptides for fragmentation by CID. Multistage activation was enabled to fragment product ions resulting from neutral loss of phosphoric acid. Quantification was performed using Progenesis LC-MS/MS software.

\section{Single-molecule stretching}

DNA fragments encoding the talin R7R8 domain (residues 1361-1654 of TLN1_MOUSE), talin R7 (residues 1361-1462 and 1578-1658 of TLN1_MOUSE), and talin R7R8 ${ }^{\text {S1589D }}$ (residues 1361-1654 of TLN1_MOUSE with an S1589D mutation) were synthesized by IDT block or PCR from template DNA. Each target DNA fragment was then assembled with a template vector (pET151: AviTag-(I27) ${ }_{2}$-Target-(I27) ${ }_{2}$-SpyTag) containing an AviTag at the N-terminus, a SpyTag at the C-terminus, and four repeats of titin I27 domains as a molecular handle using NEBuilder HiFi DNA assembly. The sequence of all plasmids was verified by first base sequencing service. Each plasmid was cotransformed with a BirA plasmid and expressed in E. coli BL21(DE3) cultured in LB-media with D-biotin and affinity purified using the 6His-Tag.

All single-molecule stretching experiments were performed using magnetic tweezers (63-65) in standard buffered solution comprising PBS, $1 \%(\mathrm{w} / \mathrm{v})$ bovine serum albumin, $2 \mathrm{mM}$ dithiothreitol, $10 \mathrm{mM}$ sodium L-ascorbate at $21^{\circ} \mathrm{C} \pm 1 \mathrm{deg}$. $\mathrm{C}$. The height of the target molecule-tethered superparamagnetic bead from the coverslip surface was recorded. At a constant applied force, the bead height change was the same as the molecule extension change (66). During linear force-increase/ force-decrease scans with typical loading rates of 0.1 to $10 \mathrm{pN}$ $\mathrm{s}^{-1}$, the stepwise bead height change was the same as the stepwise extension change of the molecule. Over the time window of the stepwise transition event $(\leq 0.01 \mathrm{~s}$, the temporal resolution of this setup), the force change $(\leq 0.001-0.1 \mathrm{pN})$ was negligible. Force calibration of the magnetic tweezer has $\sim 10 \%$ uncertainty due to the heterogeneity of the paramagnetic beads (63). Each single-molecule protein construct contained a biotinylated AviTag at its N-terminus, a target domain spanned between four repeats of titin I27 domains, and a SpyTag at its C-terminus (67). Between each two neighboring molecular components in the construct, a short linker, GGGSG, was included to ensure flexibility of the components. The C-terminus of the protein construct was specifically attached to a SpyCatcher-coated coverslip surface (Paul Marienfield), and the $\mathrm{N}$-terminus of the construct was attached to a biotinylated DNA-coated paramagnetic bead (2.8 $\mu \mathrm{m}$ diameter, Invitrogen) via a biotin-neutravidin interaction. The four repeats of I27 domains and the DNA handle acted as a molecular spacer to avoid nonspecific bead-surface interactions. The I27 domain has an ultrahigh mechanical stability in that it typically unfolds at $>100 \mathrm{pN}$ with a characteristic step size of $\sim 24 \mathrm{~nm}$ at force loading rates 1 to $5 \mathrm{pN} \mathrm{s}^{-1}$ (68). Hence it can be distinguished from the target domain unfolding signals and does not affect the probing and characterization of the target domains.

\section{Data availability}

The atomic coordinates were deposited with the Protein Data Bank, accession code 6TWN.

The talin-1-GFP-Trap mass spectrometry proteomics data are given in Table S1 and have been deposited to the ProteomeXchange Consortium via the PRIDE (69) partner 
repository with the data set identifier PXD024634 and 10.6019/PXD024634.

The BirA*-CDK1 proximity biotinylation mass spectrometry proteomics data are given in Table $\mathrm{S} 2$ and have been deposited to the ProteomeXchange Consortium via the PRIDE (69) partner repository with the data set identifier PXD024796 and 10.6019/PXD024796.

All other data are contained within the article and the accompanying supporting information.

Supporting information-This article contains supporting information (54).

Acknowledgments-We thank David Critchley for critical reading of the manuscript.

Author contributions-R. E. G., M. C. J., M. J. H., and B. T. G. conceptualization; R. E. G., M. C. J., T. Z., S. L., M. Y., and B. T. G. data curation; R. E. G., M. C. J., T. Z., G. J., S. P. M., J. Y., J. D. H., C. J., M. J. H., and B. T. G. formal analysis; M. J. H. and B. T. G. funding acquisition; R. E. G., M. C. J., T. Z., S. L., M. Y., G. J., J. Y., J. D. H., C. J., M. J. H., and B. T. G. investigation; R. E. G., M. C. J., T. Z., S. L., M. Y., G. J., J. Y., J. D. H., C. J., M. J. H., and B. T. G. methodology; M. J. H. and B. T. G. project administration; B. T. G. resources; B. T. G. validation; B. T. G. visualization; S. P. M., J. D. H., C. J., M. J. H., and B. T. G. supervision; R. E. G., M. C. J., M. J. H., and B. T. G. writing-original draft; R. E. G., M. C. J., T. Z., S. L., M. Y., G. J., J. Y., J. D. H., C. J., M. J. H., and B. T. G. writing-review and editing.

Funding and additional information-B. T. G. was funded by BBSRC (BB/N007336/1 and BB/S007245/1) and HFSP (RGP00001/ 2016). M. J. H. and C. J. were funded by Cancer Research UK (C13329/A21671). C. J. is also funded by a Cancer Research UK Institute Award (A19258), Cancer Research UK (A25236), Rosetrees Trust (M286), and European Research Council (ERC-2017COG 772577). R. E. G. was funded by a University of Kent studentship. T. Z. is funded by a Wellcome Trust ISSF Research Fellowship (204825/Z/16/Z). G. J. was supported by grants from the Sigrid Juselius Foundation, the Cancer Society of Finland, and Åbo Akademi University Research Foundation (G. J., CoE CellMech) and by Drug Discovery and Diagnostics strategic funding to Åbo Akademi University (G. J.).

Conflict of interest-The authors declare that they have no conflicts of interest with the contents of this article.

Abbreviations-The abbreviations used are: CDK1, cyclin-dependent kinase-1; CID, collision-induced dissociation; ECM, extracellular matrix; IAC, integrin adhesion complex; LC-MS/MS, liquid chromatography-tandem MS; PTM, posttranslational modification; TIRF, total internal reflection fluorescence.

\section{References}

1. Assoian, R. K. (1997) Anchorage-dependent cell cycle progression. J. Cell Biol. 136, 1-4

2. Walker, J. L., and Assoian, R. K. (2005) Integrin-dependent signal transduction regulating cyclin D1 expression and G1 phase cell cycle progression. Cancer Metastasis Rev. 24, 383-393

3. Meredith, J. E., Fazeli, B., and Schwartz, M. A. (1993) The extracellular matrix as a cell survival factor. Mol. Biol. Cell 4, 953-961
4. Frisch, S. M., and Ruoslahti, E. (1997) Integrins and anoikis. Curr. Opin. Cell Biol. 9, 701-706

5. Lesman, A., Notbohm, J., Tirrell, D. A., and Ravichandran, G. (2014) Contractile forces regulate cell division in three-dimensional environments. J. Cell Biol. 205, 155-162

6. Fededa, J. P., and Gerlich, D. W. (2012) Molecular control of animal cell cytokinesis. Nat. Cell Biol. 14, 440-447

7. Lancaster, O. M., and Baum, B. (2014) Shaping up to divide: Coordinating actin and microtubule cytoskeletal remodelling during mitosis. Semin. Cell Dev. Biol. 34, 109-115

8. Cadart, C., Zlotek-Zlotkiewicz, E., Le Berre, M., Piel, M., and Matthews, H. K. (2014) Exploring the function of cell shape and size during mitosis. Dev. Cell 29, 159-169

9. Toyoshima, F., and Nishida, E. (2007) Spindle orientation in animal cell mitosis: Roles of integrin in the control of spindle axis. J. Cell. Physiol. 213, 4.07-411

10. Lancaster, O. M., LeBerre, M., Dimitracopoulos, A., Bonazzi, D., ZlotekZlotkiewicz, E., Picone, R., Duke, T., Piel, M., and Baum, B. (2013) Mitotic rounding alters cell geometry to ensure efficient bipolar spindle formation. Dev. Cell 25, 270-283

11. Théry, M., Racine, V., Pépin, A., Piel, M., Chen, Y., Sibarita, J. B., and Bornens, M. (2005) The extracellular matrix guides the orientation of the cell division axis. Nat. Cell Biol. 7, 947-953

12. Jones, M. C., Askari, J. A., Humphries, J. D., and Humphries, M. J. (2018) Cell adhesion is regulated by CDK1 during the cell cycle. J. Cell Biol. 217, 3203-3218

13. Dao, V. T., Dupuy, A. G., Gavet, O., Caron, E., and de Gunzburg, J. (2009) Dynamic changes in Rap1 activity are required for cell retraction and spreading during mitosis. J. Cell Sci. 122, 2996-3004.

14. Marchesi, S., Montani, F., Deflorian, G., D’Antuono, R., Cuomo, A., Bologna, S., Mazzoccoli, C., Bonaldi, T., DiFiore, P. P., and Nicassio, F. (2014) DEPDC1B coordinates de-adhesion events and cell-cycle progression at mitosis. Dev. Cell 31, 420-433

15. Lim, S., and Kaldis, P. (2013) Cdks, cyclins and CKIs: Roles beyond cell cycle regulation. Development 140, 3079-3093

16. Robertson, J., Jacquemet, G., Byron, A., Jones, M. C., Warwood, S., Selley, J. N., Knight, D., Humphries, J. D., and Humphries, M. J. (2015) Defining the phospho-adhesome through the phosphoproteomic analysis of integrin signalling. Nat. Commun. 6, 1-13

17. Goult, B. T., Zacharchenko, T., Bate, N., Tsang, R., Hey, F., Gingras, A. R., Elliott, P. R., Roberts, G. C. K., Ballestrem, C., Critchley, D. R., and Barsukov, I. L. (2013) RIAM and vinculin binding to talin are mutually exclusive and regulate adhesion assembly and turnover. J. Biol. Chem. 288, 8238-824.9

18. Tadokoro, S., Shattil, S. J., Eto, K., Tai, V., Liddington, R. C., De Pereda, J. M., Ginsberg, M. H., and Calderwood, D. A. (2003) Talin binding to integrin $\beta$ tails: A final common step in integrin activation. Science 302, 103-106

19. García-Alvarez, B., De Pereda, J. M., Calderwood, D. A., Ulmer, T. S., Critchley, D., Campbell, I. D., Ginsberg, M. H., and Liddington, R. C. (2003) Structural determinants of integrin recognition by talin. Mol. Cell 11, 49-58

20. Calderwood, D. A., Zent, R., Grant, R., Rees, D. J. G., Hynes, R. O., and Ginsberg, M. H. (1999) The talin head domain binds to integrin $\beta$ subunit cytoplasmic tails and regulates integrin activation. J. Biol. Chem. 274, 28071-28074.

21. Anthis, N. J., Wegener, K. L., Ye, F., Kim, C., Goult, B. T., Lowe, E. D., Vakonakis, I., Bate, N., Critchley, D. R., Ginsberg, M. H., and Campbell, I. D. (2009) The structure of an integrin/talin complex reveals the basis of inside-out signal transduction. Eur. Mol. Biol. Organ. J. 28, 3623-3632

22. Hemmings, L., Rees, D. J., Ohanian, V., Bolton, S. J., Gilmore, A. P., Patel, B., Priddle, H., Trevithick, J. E., Hynes, R. O., and Critchley, D. R. (1996) Talin contains three actin-binding sites each of which is adjacent to a vinculin-binding site. J. Cell Sci. 109, 2715-2726

23. Atherton, P., Stutchbury, B., Wang, D.-Y., Jethwa, D., Tsang, R., MeilerRodriguez, E., Wang, P., Bate, N., Zent, R., Barsukov, I. L., Goult, B. T., Critchley, D. R., and Ballestrem, C. (2015) Vinculin controls talin engagement with the actomyosin machinery. Nat. Commun. 6, 10038 
24. Winograd-Katz, S. E., Fässler, R., Geiger, B., and Legate, K. R. (2014) The integrin adhesome: From genes and proteins to human disease. Nat. Rev. Mol. Cell Biol. 15, 273-288

25. Horton, E. R., Byron, A., Askari, J. A., Ng, D. H. J., Millon-Frémillon, A., Robertson, J., Koper, E. J., Paul, N. R., Warwood, S., Knight, D., Humphries, J. D., and Humphries, M. J. (2015) Definition of a consensus integrin adhesome and its dynamics during adhesion complex assembly and disassembly. Nat. Cell Biol. 17, 1577-1587

26. Chastney, M. R., Lawless, C., Humphries, J. D., Warwood, S., Jones, M. C., Knight, D., Jorgensen, C., and Humphries, M. J. (2020) Topological features of integrin adhesion complexes revealed by multiplexed proximity biotinylation. J. Cell Biol. 219, e202003038

27. Goult, B. T., Yan, J., and Schwartz, M. A. (2018) Talin as a mechanosensitive signaling hub. J. Cell Biol. 217, 3776-3784.

28. Horton, E. R., Astudillo, P., Humphries, M. J., and Humphries, J. D. (2016) Mechanosensitivity of integrin adhesion complexes: Role of the consensus adhesome. Exp. Cell Res. 343, 7-13

29. Alam, T., Alazmi, M., Gao, X., and Arold, S. T. (2014) How to find a leucine in a haystack? Structure, ligand recognition and regulation of leucine-aspartic acid (LD) motifs. Biochem. J. 460, 317-329

30. Brown, M. C., Curtis, M. S., and Turner, C. E. (1998) Paxillin LD motifs may define a new family of protein recognition domains. Nat. Struct. Mol. Biol. 5, 677-678

31. Gough, R. E., and Goult, B. T. (2018) The tale of two talins - two isoforms to fine-tune integrin signalling. FEBS Lett. 592, 2108-2125

32. Zacharchenko, T., Qian, X., Goult, B. T., Jethwa, D., Almeida, T. B., Ballestrem, C., Critchley, D. R., Lowy, D. R., and Barsukov, I. L. (2016) LD motif recognition by talin: Structure of the talin-DLC1 complex. Structure 24, 1130-1141

33. Whitewood, A. J., Singh, A. K., Brown, D. G., and Goult, B. T. (2018) Chlamydial virulence factor TarP mimics talin to disrupt the talinvinculin complex. FEBS Lett. 592, 1751-1760

34. Bouchet, B. P., Gough, R. E., Ammon, Y. C., van de Willige, D., Post, H., Jacquemet, G., Altelaar, A. M., Heck, A. J. R., Goult, B. T., and Akhmanova, A. (2016) Talin-KANK1 interaction controls the recruitment of cortical microtubule stabilizing complexes to focal adhesions. Elife 5, e18124

35. Kumar, A., Ouyang, M., Van den Dries, K., McGhee, E. J., Tanaka, K., Anderson, M. D., Groisman, A., Goult, B. T., Anderson, K. I., and Schwartz, M. A. (2016) Talin tension sensor reveals novel features of focal adhesion force transmission and mechanosensitivity. J. Cell Biol. 213, 371-383

36. Gingras, A. R., Bate, N., Goult, B. T., Hazelwood, L., Canestrelli, I., Grossmann, J. G., Liu, H., Putz, N. S. M., Roberts, G. C. K., Volkmann, N., Hanein, D., Barsukov, I. L., and Critchley, D. R. (2008) The structure of the C-terminal actin-binding domain of talin. $E M B O J .27$, $458-469$

37. McCann, R. O., and Craig, S. W. (1997) The I/LWEQ module: A conserved sequence that signifies F-actin binding in functionally diverse proteins from yeast to mammals. Proc. Natl. Acad. Sci. U. S. A. 94, 56795684

38. Gingras, A. R., Bate, N., Goult, B. T., Patel, B., Kopp, P. M., Emsley, J., Barsukov, I. L., Roberts, G. C. K., and Critchley, D. R. (2010) Central region of talin has a unique fold that binds vinculin and actin. J. Biol. Chem. 285, 29577-29587

39. Chang, Y. C., Zhang, H., Franco-Barraza, J., Brennan, M. L., Patel, T., Cukierman, E., and Wu, J. (2014) Structural and mechanistic insights into the recruitment of talin by RIAM in integrin signaling. Structure 22, $1810-1820$

40. Hoellerer, M. K., Noble, M. E. M., Labesse, G., Campbell, I. D., Werner, J. M., and Arold, S. T. (2003) Molecular recognition of paxillin LD motifs by the focal adhesion targeting domain. Structure 11, 1207-1217

41. Brown, N. R., Korolchuk, S., Martin, M. P., Stanley, W. A., Moukhametzianov, R., Noble, M. E. M., and Endicott, J. A. (2015) CDK1 structures reveal conserved and unique features of the essential cell cycle CDK. Nat. Commun. 6, 1-12

42. McGrath, D. A., Balog, E. R. M., Kõivomägi, M., Lucena, R., Mai, M. V., Hirschi, A., Kellogg, D. R., Loog, M., and Rubin, S. M. (2013) Cks confers specificity to phosphorylation-dependent CDK signaling pathways. Nat. Struct. Mol. Biol. 20, 1407-1414.

43. Yao, M., Goult, B. T., Klapholz, B., Hu, X., Toseland, C. P., Guo, Y., Cong, P., Sheetz, M. P., and Yan, J. (2016) The mechanical response of talin. Nat. Commun. 7, 11966

44. Yan, J., Yao, M., Goult, B. T., and Sheetz, M. P. (2015) Talin dependent mechanosensitivity of cell focal adhesions. Cell. Mol. Bioeng. $8,151-159$

45. Bian, Y., Song, C., Cheng, K., Dong, M., Wang, F., Huang, J., Sun, D., Wang, L., Ye, M., and Zou, H. (2014) An enzyme assisted RP-RPLC approach for in-depth analysis of human liver phosphoproteome. J. Proteomics 96, 253-262

46. Mertins, P., Mani, D. R., Ruggles, K. V., Gillette, M. A., Clauser, K. R., Wang, P., Wang, X., Qiao, J. W., Cao, S., Petralia, F., Kawaler, E., Mundt, F., Krug, K., Tu, Z., Lei, J. T., et al. (2016) Proteogenomics connects somatic mutations to signalling in breast cancer. Nature 534, 55-62

47. Mertins, P., Yang, F., Liu, T., Mani, D. R., Petyuk, V. A., Gillette, M. A., Clauser, K. R., Qiao, J. W., Gritsenko, M. A., Moore, R. J., Levine, D. A., Townsend, R., Erdmann-Gilmore, P., Snider, J. E., Davies, S. R., et al. (2014) Ischemia in tumors induces early and sustained phosphorylation changes in stress kinase pathways but does not affect global protein levels. Mol. Cell. Proteomics 13, 1690-1704.

48. Haining, A. W. M., Rahikainen, R., Cortes, E., Lachowski, D., Rice, A., von Essen, M., Hytönen, V. P., and del Río Hernández, A. (2018) Mechanotransduction in talin through the interaction of the R8 domain with DLC1. PLoS Biol. 16, e2005599

49. Yang, J., Zhu, L., Zhang, H., Hirbawi, J., Fukuda, K., Dwivedi, P., Liu, J., Byzova, T., Plow, E. F., Wu, J., and Qin, J. (2014) Conformational activation of talin by RIAM triggers integrin-mediated cell adhesion. Nat. Commun. 5, 5880

50. Sun, Z., Tseng, H.-Y., Tan, S., Senger, F., Kurzawa, L., Dedden, D., Mizuno, N., Wasik, A. A., Thery, M., Dunn, A. R., and Fässler, R. (2016) Kank2 activates talin, reduces force transduction across integrins and induces central adhesion formation. Nat. Cell Biol. 18, 941-953

51. [preprint] Han, S. J., Azarova, E. V., Whitewood, A. J., Bachir, A., Guttierrez, E., Groisman, A., Horwitz, A. R., Goult, B. T., Dean, K. M., and Danuser, G. (2021) Talin-vinculin precomplex drives adhesion maturation by accelerated force transmission and vinculin recruitment. bioRxiv. https://doi.org/10.1101/735183

52. Desai, D., Wessling, H. C., Fisher, R. P., and Morgan, D. O. (1995) Effects of phosphorylation by CAK on cyclin binding by CDC2 and CDK2. Mol. Cell. Biol. 15, 345-350

53. Goult, B. T. (2021) The mechanical basis of memory-the MeshCODE theory. Front. Mol. Neurosci. 14, 1-18

54. Kumar, M., Gouw, M., Michael, S., Sámano-Sánchez, H., Pancsa, R., Glavina, J., Diakogianni, A., Valverde, J. A., Bukirova, D., Signalyševa, J., Palopoli, N., Davey, N. E., Chemes, L. B., and Gibson, T. J. (2020) ELMthe eukaryotic linear motif resource in 2020. Nucleic Acids Res. 48, D296D306

55. Khan, R. B., Varela, L., Cowell, A. R., and Goult, B. T. (2021) Biochemical characterization of the integrin interactome. Methods Mol. Biol. 2217, 115-147

56. Skinner, S. P., Goult, B. T., Fogh, R. H., Boucher, W., Stevens, T. J., Laue, E. D., and Vuister, G. W. (2015) Structure calculation, refinement and validation using CcpNmr analysis. Acta Crystallogr. D Biol. Crystallogr. 71, 154-161

57. McCoy, A. J., Grosse-Kunstleve, R. W., Adams, P. D., Winn, M. D., Storoni, L. C., and Read, R. J. (2007) Phaser crystallographic software. J. Appl. Crystallogr. 40, 658-674.

58. Liebschner, D., Afonine, P. V., Baker, M. L., Bunkóczi, G., Chen, V. B., Croll, T. I., Hintze, B., Hung, L.-W., Jain, S., McCoy, A. J., Moriarty, N. W., Oeffner, R. D., Poon, B. K., Prisant, M. G., Read, R. J., et al. (2019) Macromolecular structure determination using X-rays, neutrons and electrons: Recent developments in Phenix. Acta Crystallogr. D Struct. Biol. 75, 861-877

59. Emsley, P., Lohkamp, B., Scott, W. G., and Cowtan, K. (2010) Features and development of Coot. Acta Crystallogr. D Biol. Crystallogr. 66, 486501 


\section{A direct interaction between talin and CDK1}

60. Humphries, J. D., Byron, A., Bass, M. D., Craig, S. E., Pinney, J. W., Knight, D., and Humphries, M. J. (2009) Proteomic analysis of integrinassociated complexes identifies RCC2 as a dual regulator of Rac1 and Arf6. Sci. Signal. 2, ra51

61. Roux, K. J., Kim, D. I., Raida, M., and Burke, B. (2012) A promiscuous biotin ligase fusion protein identifies proximal and interacting proteins in mammalian cells. J. Cell Biol. 196, 801-810

62. Roux, K. J., Kim, D. I., Burke, B., and May, D. G. (2018) BioID: A screen for protein-protein interactions. Curr. Protoc. Protein Sci. 91, 19.23.1-19. 23.15

63. Chen, H., Fu, H., Zhu, X., Cong, P., Nakamura, F., and Yan, J. (2011) Improved high-force magnetic tweezers for stretching and refolding of proteins and short DNA. Biophys. J. 100, 517-523

64. Le, S., Liu, R., Lim, C. T., and Yan, J. (2016) Uncovering mechanosensing mechanisms at the single protein level using magnetic tweezers. Methods 94, 13-18

65. Le, S., Yao, M., Chen, J., Efremov, A. K., Azimi, S., and Yan, J. (2015) Disturbance-free rapid solution exchange for magnetic tweezers singlemolecule studies. Nucleic Acids Res. 43, e113
66. Zhao, X., Zeng, X., Lu, C., and Yan, J. (2017) Studying the mechanical responses of proteins using magnetic tweezers. Nanotechnology 28, 414002

67. Zakeri, B., Fierer, J. O., Celik, E., Chittock, E. C., Schwarz-Linek, U., Moy, V. T., and Howarth, M. (2012) Peptide tag forming a rapid covalent bond to a protein, through engineering a bacterial adhesin. Proc. Natl. Acad. Sci. U. S. A. 109, E690-E697

68. Yuan, G., Le, S., Yao, M., Qian, H., Zhou, X., Yan, J., and Chen, H. (2017) Elasticity of the transition state leading to an unexpected mechanical stabilization of titin immunoglobulin domains. Angew. Chem. Int. Ed. Engl. 56, 54.90-5493

69. Perez-Riverol, Y., Csordas, A., Bai, J., Bernal-Llinares, M., Hewapathirana, S., Kundu, D. J., Inuganti, A., Griss, J., Mayer, G., Eisenacher, M., Pérez, E., Uszkoreit, J., Pfeuffer, J., Sachsenberg, T., Yilmaz, S.., et al. (2019) The PRIDE database and related tools and resources in 2019: Improving support for quantification data. Nucleic Acids Res. 47, D442D450

70. Goedhart, J., and Luijsterburg, M. S. (2020) VolcaNoseR is a web app for creating, exploring, labeling and sharing volcano plots. Sci. Rep. 10, 1-5 